\title{
Foxp2 loss of function increases striatal direct pathway inhibition via increased GABA release
}

\author{
Jon-Ruben van Rhijn ${ }^{1,2,3} \cdot$ Simon E. Fisher ${ }^{3,4} \cdot$ Sonja C. Vernes ${ }^{2,4} \cdot$ Nael Nadif Kasri ${ }^{1,5} \mathbb{C}$
}

Received: 8 March 2018 / Accepted: 31 August 2018 / Published online: 5 September 2018

(c) The Author(s) 2018

\begin{abstract}
Heterozygous mutations of the Forkhead-box protein 2 (FOXP2) gene in humans cause childhood apraxia of speech. Loss of Foxp2 in mice is known to affect striatal development and impair motor skills. However, it is unknown if striatal excitatory/ inhibitory balance is affected during development and if the imbalance persists into adulthood. We investigated the effect of reduced Foxp2 expression, via a loss-of-function mutation, on striatal medium spiny neurons (MSNs). Our data show that heterozygous loss of Foxp2 decreases excitatory (AMPA receptor-mediated) and increases inhibitory (GABA receptor-mediated) currents in D1 dopamine receptor positive MSNs of juvenile and adult mice. Furthermore, reduced Foxp2 expression increases GAD67 expression, leading to both increased presynaptic content and release of GABA. Finally, pharmacological blockade of inhibitory activity in vivo partially rescues motor skill learning deficits in heterozygous Foxp2 mice. Our results suggest a novel role for Foxp2 in the regulation of striatal direct pathway activity through managing inhibitory drive.
\end{abstract}

Keywords Foxp2 $\cdot$ Excitatory-inhibitory balance $\cdot$ Neurodevelopment $\cdot$ D1R-MSN $\cdot$ Striatum

\section{Introduction}

Sonja C. Vernes and Nael Nadif Kasri contributed equally to this work.

Electronic supplementary material The online version of this article (https://doi.org/10.1007/s00429-018-1746-6) contains supplementary material, which is available to authorized users.

Sonja C. Vernes

Sonja.vernes@mpi.nl

$\bowtie$ Nael Nadif Kasri

n.nadif@donders.ru.nl

1 Department of Cognitive Neuroscience, Donders Institute for Brain, Cognition and Behaviour, Radboudumc, 6525 HR Nijmegen, The Netherlands

2 Neurogenetics of Vocal Communication Group, Max Planck Institute for Psycholinguistics, 6525 XD Nijmegen, The Netherlands

3 Language and Genetics Department, Max Planck Institute for Psycholinguistics, 6525 XD Nijmegen, The Netherlands

4 Donders Institute for Brain, Cognition and Behaviour, 6525 HR Nijmegen, The Netherlands

5 Department of Human Genetics, Donders Institute for Brain, Cognition, and Behaviour, Radboudumc, 6525 GA Nijmegen, The Netherlands
Balanced neuronal activity between cortex, striatum and thalamus is essential for the generation of voluntary movements (Shepherd 2013). Imbalanced activity within the striatum is known to disrupt complex motor behaviors, such as the production of spoken language (Peach 2004; SquareStorer et al. 1990). FOXP2, the first single gene linked to a speech and language disorder (Lai et al. 2001), is important for the correct execution of complex motor behaviors used for speech. Individuals with mutations in the FOXP2 gene have problems executing coordinated sequences of orofacial movements, which impede their speech [diagnosed as developmental verbal dyspraxia or childhood apraxia of speech (CAS)], while their general cognitive functioning and other aspects of motor coordination are usually less severely affected (MacDermot et al. 2005; Morgan et al. 2017). Mice with heterozygous Foxp 2 mutations display impairments in motor skill learning, shown by decreased performance on the accelerating rotarod (French et al. 2012; Groszer et al. 2008), suggesting that similar neurobiological substrates could underlie the behavioral phenotypes in human and mouse. FoxP2 codes for a transcription factor (Devanna et al. 2014; Vernes et al. 2006, 2007) and plays important roles during the early development of the central 
nervous system as well as in the postnatal brain (Spiteri et al. 2007; Vernes et al. 2011; Groszer et al. 2008). Mutations of this gene affect both cortical and striatal activity in human cases and animal models (French et al. 2012; Groszer et al. 2008; Liegeois et al. 2003). Of particular note, striatal longterm depression is affected in adult mice with heterozygous Foxp2 mutations (Groszer et al. 2008; Enard et al. 2009), which suggests that Foxp2 regulates molecular mechanisms involved in synaptic plasticity. Additionally, evidence from in vivo recordings shows that Foxp2 mutant mice display abnormal ongoing striatal activity and dysregulated firing rates during a motor-learning task (French et al. 2012). Finally, Foxp2 has been reported to regulate genes involved in synapse formation (Sia et al. 2013; Vernes et al. 2011) and was recently shown to affect excitatory synaptic activity during early postnatal development through inhibition of the $M e f 2 c$ gene (Chen et al. 2016).

Studies using mouse models to investigate the functions of Foxp2 have made use of two well described mutations which differentially affect Foxp2 and are similar to mutations described in patients with CAS. These mutations lead to either disruption of the DNA binding domain of Foxp2, or a loss of function stop-gain mutation in exon 7 that causes nonsense mediated decay of Foxp2 protein (MacDermot et al. 2005; Morgan et al. 2017). Though neurobiological mechanisms affected by these different mutations could differ, there is currently no data to suggest this. Moreover, heterozygous Foxp2 mice with either the DNA binding domain mutation or the loss of function mutation display similar impairments in motor skill learning (French et al. 2012; Enard et al. 2009; Groszer et al. 2008).

To date, investigations into the functions of Foxp2 in striatum have focused on how Foxp2 affects excitatory activity (Groszer et al. 2008; Enard et al. 2009; French et al. 2012; Chen et al. 2016; Schreiweis et al. 2014). Although the striatum receives numerous excitatory connections from the cortex (Shepherd 2013) and thalamus (Smith et al. 2004, 2009), it is itself entirely composed of inhibitory neurons (Kreitzer and Malenka 2008). GABAergic medium spiny neurons (MSNs) make up 95\% of the striatum, and two major populations can be distinguished: MSNs that express either the D1 dopamine receptor (D1R-MSNs) or the D2 dopamine receptor (D2R-MSNs) (Gittis and Kreitzer 2012). These MSN populations differentially affect the downstream neural sites to which they ultimately project, and each regulate separate aspects of motor behavior (Calabresi et al. 2014; Surmeier et al. 2007; Gittis and Kreitzer 2012). D1RMSNs innervate the direct pathway, which leads to increased activation of the cortico-striatal-thalamic motor circuit. In contrast, D2R-MSNs belong to the indirect pathway, inactivating this motor circuit. Balanced excitation and inhibition (E/I balance) of cells within both striatal pathways is crucial for the generation of complex motor behaviors (Schroll et al. 2015).

How Foxp2 affects neuronal function has been investigated in both early development and adulthood, but knowledge of how Foxp2 affects striatal circuits during (motor) development is lacking. This is especially important to address since $\mathrm{E} / \mathrm{I}$ balance is dynamic. Changes in $\mathrm{E} / \mathrm{I}$ balance during development are tightly regulated and have been described in multiple cell types in hippocampus (Liu 2004) and cortex (Zhang et al. 2011) of juvenile mice. A disrupted E/I balance during development can severely affect adult behavior (Peixoto et al. 2016). Indeed, aberrant E/I balance in striatal cells is known to lead to impaired motor learning in adult mice (Rothwell et al. 2014), similar to the deficits observed in adult mice with mutations in Foxp2 (French et al. 2012; Groszer et al. 2008).

We examined the effects of reduced Foxp2 expression from early development into adulthood in the striatum, using a heterozygous mouse model for the stop-gain Foxp2 mutation (S321X). Foxp2 protein expression is absent in Foxp $2^{S 321 X / S 321 X}$ mice and reduced to intermediate levels in Foxp $2^{S 321 X /+}$ mice (Groszer et al. 2008; Vernes et al. 2011). We provide evidence that Foxp2 plays a role in the regulation of striatal E/I balance, regulates inhibitory activity through repression of GAD67, and regulates inhibitory presynaptic strength of D1R-MSNs, but not D2R-MSNs. Finally, we show that pharmacological blockade of striatal inhibition partially rescues the motor skill learning deficits observed in heterozygous Foxp 2 mutant mice. Taken together, our results reveal a developmental circuit defect caused by reduced levels of functional Foxp2, which suggests that E/I imbalances in striatal activity may contribute to (vocal) motor problems in humans with FOXP2 mutations.

\section{Results}

\section{Reduced Foxp2 expression affects D1R-MSN excitatory synaptic inputs}

Previous studies have suggested that Foxp2 is differentially expressed in D1R- versus D2R-expressing MSNs in the striatum (Vernes et al. 2011). To directly assess the expression of Foxp2 in D1R- and D2R-MSNs, we performed immunocytochemistry for Foxp2 on mice containing bacterial artificial chromosome (BAC)-TRAP GFP constructs (Heiman et al. 2008; Doyle et al. 2008) under the D1R or D2R promoter, which have been shown to faithfully label D1R- or D2R-expressing MSNs, respectively (Heiman et al. 2008). Upon investigation of expression in juvenile mice (PND1114) we found that Foxp2 is expressed in nearly all striatal D1R-MSNs, in contrast to only a small fraction of D2RMSN (Fig. 1a). 
We next investigated whether heterozygous Foxp2 loss of function differentially affects striatal MSN subtypes at the synaptic level. To enable a targeted single-cell characterization of how reduced Foxp2 expression affects striatal activity, we crossed Foxp $2^{S 32 I X /+}$ mice with (BAC)-TRAP D1R-GFP mice. We performed patch-clamp recordings on GFP-positive D1R-MSNs and non-GFP putative D2RMSNs. Although Foxp2 expressing MSNs are spread throughout the striatum, we chose to focus on cells in the dorsolateral striatum, because of its connection to the motor cortex (Hunnicutt et al. 2016). Moreover, previous experiments regarding Foxp2 function have shown aberrant activity in dorsal striatum of heterozygous Foxp2 mutant/ knockout mice (French et al. 2012; Groszer et al. 2008; Reimers-Kipping et al. 2011), and reduced motor skill learning suggests areas involved in motor control might be more severely affected by reduced Foxp2 expression. We measured excitatory synaptic strength through glutamatergic $\alpha$-amino-3-hydroxy-5-methyl-4-isoxazolepropionic acid (AMPA) receptor activation by analysis of miniature excitatory postsynaptic current (mEPSC) amplitude and frequency. In D1R-MSNs of heterozygous postnatal day (PND) 10-14 juvenile mice, mEPSC amplitude was reduced, whereas $\mathrm{mEPSC}$ frequency was similar between genotypes (Fig. 1c). No changes in D2R-MSN amplitude or frequency were observed (Fig. 1d). Finally, we measured AMPA/NMDA ratio in D1R-MSNs of juvenile Foxp2 $2^{+/+}$ and $F o x p 2^{S 32 X /+}$ mice. AMPA/NMDA ratio is significantly increased in Foxp $2^{S 32 X /+}$ mice, which suggests that NMDA currents are decreased as well in addition to the previously observed reduction in AMPAR-mediated activity (Suppl Fig. 1). These results show that reduced Foxp2 expression leads to decreased excitatory postsynaptic strength of only direct pathway MSNs, which is consistent with the predominant expression of Foxp2 in D1R-MSNs.

\section{Inhibitory synaptic inputs are increased in D1R-MSNs of Foxp2 ${ }^{S 321 X /+}$ mice}

Physiological effects of heterozygous Foxp2 mutations have only been investigated in the context of excitatory synaptic transmission (Chen et al. 2016; Reimers-Kipping et al. 2011; Schreiweis et al. 2014). Since E/I balance is important for the development and maintenance of neuronal circuitry, we examined the role of Foxp2 in striatal inhibition. Striatal inhibition is accomplished through extra-striatal as well as intra-striatal sources. From the cortex, GABAergic interneurons project to the striatum and provide inhibitory input (Melzer et al. 2017). However, corticostriatal GABAergic interneurons do not express Foxp2 (Chiu et al. 2014; Hisaoka et al. 2010). We, therefore, expect differences in inhibitory activity between wild-type and Foxp $2^{S 321 X /+}$ mice through changes in intra-striatal inhibition, which is regulated through MSNs and striatal interneurons (Taverna et al. 2008; Lalchandani and Vicini 2013). We measured inhibitory activity only in D1R-MSNs, since unidirectional connections between D1R-MSNs are common, while connections between D1R-MSNs and D2R-MSNs are rare (6\%) (Taverna et al. 2008). Though D2R-MSNs synapse on D1RMSNs (27\%) the lack of Foxp2 expression in D2R-MSNs, combined with the lack of an excitatory phenotype, suggests that D2R-MSNs cannot be cell-autonomously affected by Foxp2.

We measured miniature inhibitory postsynaptic currents (mIPSCs), which are mediated by GABA and reflect inhibitory synaptic strength. In D1R-MSNs of juvenile (PND1014) Foxp $2^{S 32 I X /+}$ mice, we found that mIPSC amplitude and frequency were increased compared to wild-type controls (Fig. 1e). Our data show that reduced Foxp2 expression differentially affects excitatory and inhibitory synaptic strength. There is no compensation for the decreased excitatory activity, but rather this is aggravated by increased inhibition.

\section{E/l imbalance persists in dorsolateral striatum of adult Foxp2 ${ }^{\mathrm{S321X/+}}$ mice}

In mice, Foxp2 is present during the entire lifespan (Ferland et al. 2003), and expression does not change strongly between juvenile and adult animals (Ferland et al. 2003; Takahashi et al. 2003). However, given that this gene is important for early neuronal development (Vernes et al. 2011; Chen et al. 2016), it is conceivable that functional effects of reduced Foxp2 expression differ between juvenile and adult animals. In previous studies the effects of Foxp 2 mutations on striatal physiology have only been investigated in adult (French et al. 2012; Groszer et al. 2008) or juvenile mice separately (Chen et al. 2016), and thus a developmental profile of synaptic changes due to reduced Foxp2 expression is lacking. We hypothesized that the E/I imbalance present in D1R-MSNs of juvenile Foxp $2^{S 321 X /+}$ mice might persist until adulthood, since adult Foxp2 heterozygous mice show clear deficits in motor skill learning. We measured the GABA/AMPA ratio as an index of E/I balance in juvenile PND11, PND14, PND17 as well as adult (PND60) mice, which comprises a developmental profile at ages around the critical time points for the emergence of motor coordination (Dehorter et al. 2011) and striatal synaptic integration and circuit formation in mice (Lee and Sawatari 2011). During development in wild type mice, the GABA/AMPA ratio increases sharply in D1R-MSNs (Fig. 2a). Interestingly, both during development and in adulthood the GABA/AMPA ratio of D1RMSNs was significantly higher in Foxp $2^{S 321 X /+}$ mice than in wild-type controls (Fig. 2a), which indicates that the $\mathrm{E} / \mathrm{I}$ imbalance we uncovered in juvenile mice indeed persists into adulthood. We subsequently measured mEPSCs 
a b
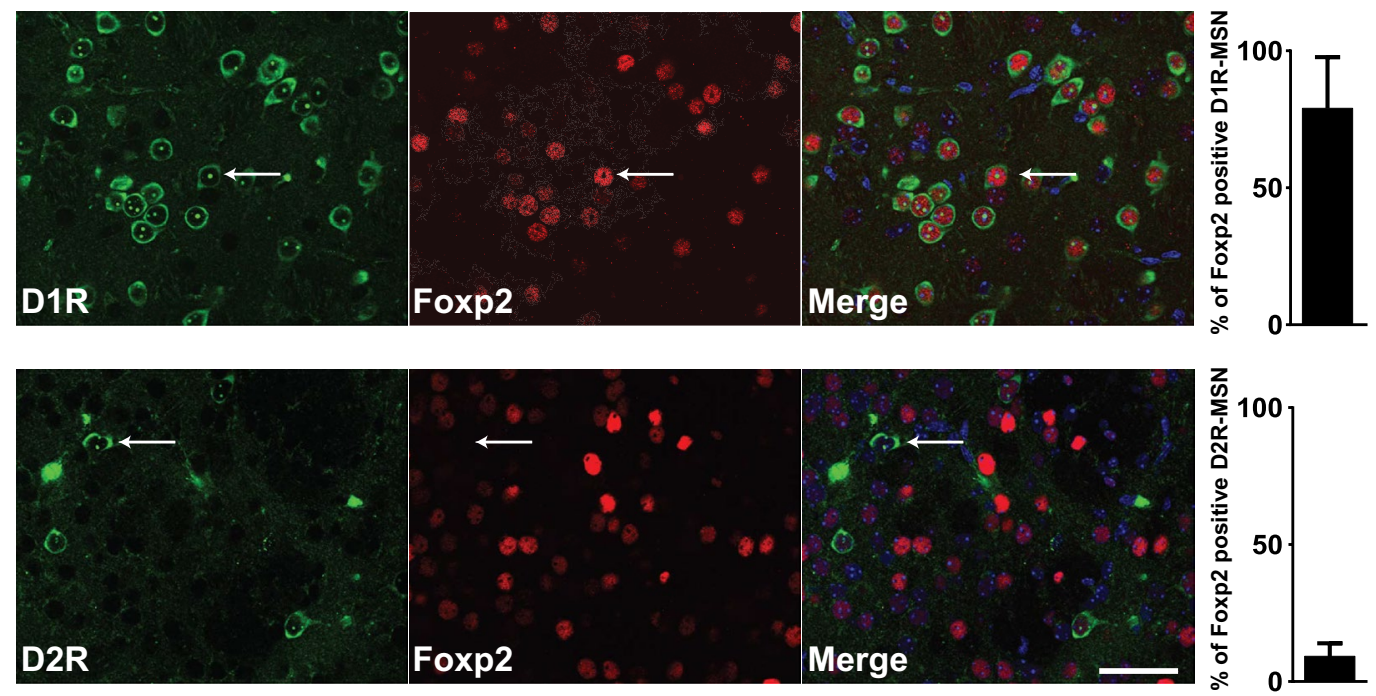

C D1R-MSN mEPSC
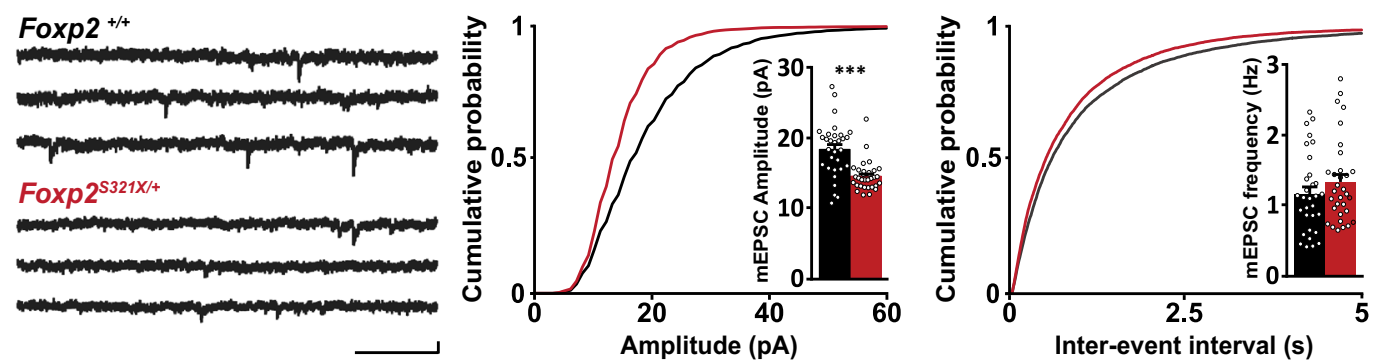

\section{d D2R-MSN mEPSC}
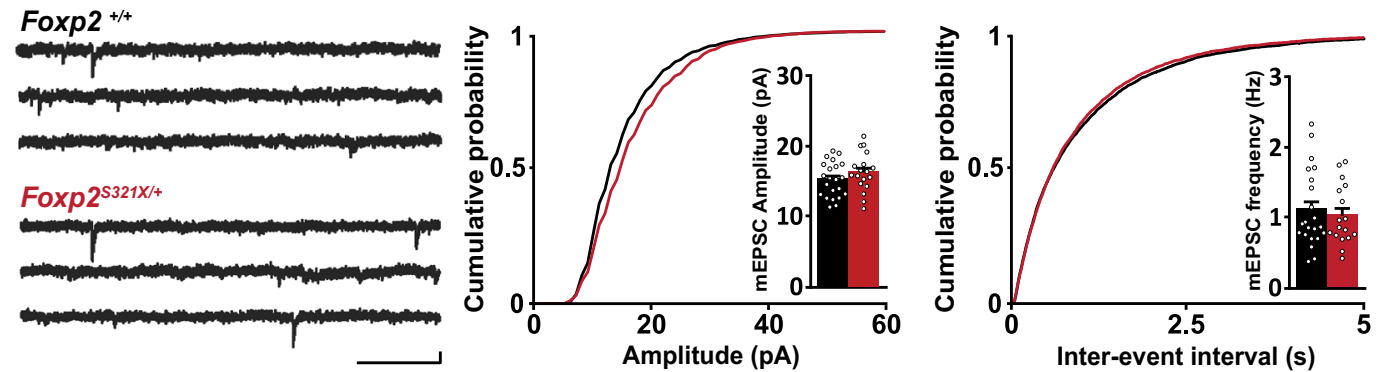

e D1R-MSN mIPSC
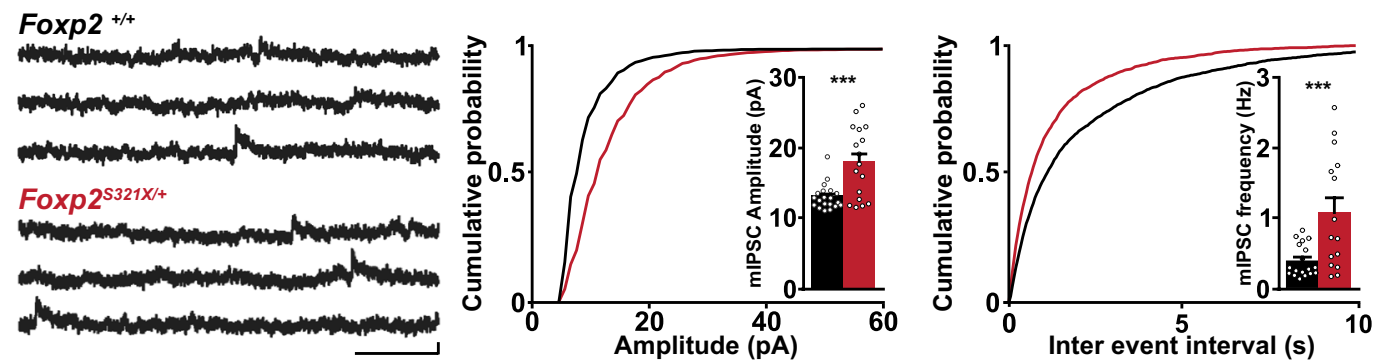
4Fig. 1 Foxp2 is predominantly expressed in D1R-MSNs in dorsolateral striatum and affects synaptic activity. a D1R-GFP, D2R-GFP and Foxp2 are expressed in a subset of striatal cells in juvenile (PND11-14) mice, arrows point to cells with overlapping D1R and Foxp2 expression (top row) or D2R expression without Foxp2 expression (bottom row). Scale bar $50 \mu \mathrm{m}$. b $83.7 \pm 16 \%$ of D1R-GFP positive cells express Foxp2, compared to $16.9 \pm 4 \%$ of D2R-GFP cells. $N / n$ number of mice/number of slices. $N / n=3 / 12$. c Striatal D1R-MSN mEPSC amplitude is decreased following reduced Foxp2 expression. Example of mEPSC activity in striatal D1R-MSNs from juvenile (PND14) Foxp $2^{+/+}$and Foxp $2^{S 32 I X /+}$ mice. Scale bar $200 \mathrm{~ms} / 20$ pA. Cumulative distribution of mEPSC amplitude $\left(F_{\text {oxp }} 2^{+/+}=19.4 \pm 0.69 \mathrm{pA}\right.$, Foxp $\left.2^{S 32 I X /+}=14.3 \pm 0.36 \quad \mathrm{pA}, \quad P<0.0001\right)$ and frequency $\left(\right.$ Foxp $^{+/+}=1.12 \pm 0.1 \mathrm{~Hz}, \quad$ Foxp $\left.2^{S 32 I X /+}=1.19 \pm 0.11 \mathrm{~Hz}, \mathrm{NS}\right)$ in striatal D1R-MSNs. Foxp $2^{+/+} N / n=3 / 31$, Foxp $2^{S 321 X /+} N / n=3 / 32$. d Example traces of mEPSC activity in striatal D2R-MSNs from juvenile (PND14) Foxp2 $2^{+/+}$and Foxp2 $2^{\text {S32IX/+ }}$ mice Scale bar $200 \mathrm{~ms} / 20 \mathrm{pA}$. Cumulative distribution of mEPSC amplitude $\left(\right.$ Foxp $^{+/+}=15.64 \pm 0.53 \mathrm{pA}$, Foxp $\left.^{S 32 I X /+}=16.14 \pm 0.62 \mathrm{pA}, \mathrm{NS}\right)$ and frequency $\left(F o x p 2^{+/+}=0.92 \pm 0.12 \mathrm{~Hz}, F o x p 2^{S 32 I X /+}=0.89 \pm 0.1 \mathrm{~Hz}\right.$, NS) in striatal D2R-MSNs. Foxp $2^{+/+} N / n=3 / 22, \quad$ Foxp $2^{S 32 I X /+}$ $N / n=3 / 19$. e Example traces of mIPSC activity in striatal D1RMSNs from juvenile (PND14) Foxp $2^{+/+}$and Foxp2 $2^{S 32 I X /+}$ mice. Scale bar $200 \mathrm{~ms} / 10 \mathrm{pA}$. Cumulative distribution of mIPSC amplitude $\quad\left(\right.$ Foxp $^{+/+}=8.6 \pm 0.27 \quad \mathrm{pA}, \quad$ Foxp $2^{S 32 I X /+}=11.9 \pm 0.83 \quad \mathrm{pA}$, $P<0.001)$ and frequency $\left(\right.$ Foxp $^{+/+}=0.18 \pm 0.036 \quad \mathrm{~Hz}$, Foxp $\left.2^{S 32 I X /+}=0.71 \pm 0.14 \mathrm{~Hz}, P<0.01\right)$ in striatal D1R-MSNs. Foxp $2^{+/+} N / n=3 / 20$, Foxp $2^{S 321 X /+} N / n=3 / 17$. *** $P<0.01$. $N$ number of mice, $n$ number of cells. All data analyzed by two-sided Students' $T$ test

and mIPSCs in D1R-MSNs of adult (PND60) Foxp $2^{S 321 X /+}$ mice to determine if the increased GABA/AMPA ratios in Foxp $2^{S 321 X /+}$ mice reflect persistent changes in excitatory and/or inhibitory synaptic strength. Our results show that the increased GABA/AMPA ratio in adult heterozygous mice is due to decreased mEPSC amplitude (Fig. 2b) coupled with an increased mIPSC amplitude (Fig. 2c). However, the increased mIPSC frequency we had observed in our juvenile mice was not present in adult mice (Fig. 2c), which indicates that some form of compensation might be present. This compensation is, however, insufficient to return activity to baseline levels and, therefore, we conclude that the changes in E/I balance are persistent into adulthood. Changes in inhibitory synaptic strength can indicate changes at either the pre- or the post-synapse, such as increased presynaptic neurotransmitter release or increased expression of postsynaptic GABA receptors, respectively. We, therefore, set out to assess the effect of reduced Foxp 2 expression on striatal synapses at the molecular level.

\section{Decreased Foxp2 expression leads to increased GAD67 expression around D1R-MSN somata}

Foxp 2 might modulate inhibitory activity by transcriptionally regulating genes involved in GABA signaling (Vernes et al. 2007, 2011; Fujita et al. 2008). One target gene identified in an in vivo chromatin immunoprecipitation (ChIP)chip screen for Foxp2 binding in mouse brain was Gad (Vernes et al. 2011), the gene that codes for GAD67, a key enzyme in the production of GABA at the synapse (Lau and Murthy 2012). By contrast, other genes involved in GABAergic activity, such as VGAT or GAD2, were not detected in this ChIP screen. Moreover, GAD2 expression has been shown to be unaltered in striatal tissue from Foxp2 heterozygous knockout embryos (French et al. 2007). Based on these findings we hypothesized that reduced Foxp2 expression could lead to changes in GAD67 expression, and thus contribute to aberrant GABAergic activity.

We compared GAD67 expression around D1R-MSN somata in the striatum of juvenile Foxp $2^{+/+}$and Foxp $2^{S 321 X /+}$ mice (Fig. 3a). GAD67 puncta surrounding striatal D1RMSNs originate mostly from D1R-MSN to D1R-MSN pairs (Taverna et al. 2008) and to a lesser extent from extrastriatal GABAergic interneurons (Melzer et al. 2017) and striatal interneurons (Taverna et al. 2008). However, of these cells only D1R-MSNs express Foxp2 (Fong et al. 2018). Thus, aberrant GAD67 expression levels can be related to changes in Foxp2 expression. This could either be through direct regulation of GAD67 expression by Foxp2 or by indirect effects of altered Foxp2 levels. Foxp2 is known to affect the development of striatal cells in primary cell culture (Vernes et al. 2011) and impaired D1R-MSN development in vivo may account for changes in protein expression, such as reduced GAD67 levels. We found that GAD67 expression was significantly increased around D1R-MSN somata in Foxp $2^{S 321 X /+}$ mice compared to wild-type controls (Fig. 3b), whilst GAD67 was not changed around D2R-MSNs (Suppl Fig. 2). Furthermore, protein expression analysis by western blot in dissected striatum from juvenile Foxp2 $2^{+/+}$and Foxp $2^{S 321 X /+}$ mice showed GAD67 expression to be increased (Fig. 3c).

To assess whether or not the increased GAD67 expression could be due to a general increase in expression of key components of GABA transmission, we quantified vesicular GABA transporter (VGAT) expression around D1RMSN somata (Fig. 3a). No change in VGAT expression was observed between Foxp $2^{+/+}$and Foxp $2^{\text {S321X/+ mice, which }}$ suggests that Foxp2 specifically regulates GAD67 but does not affect the number of synapses. The increase in GAD67 levels of mice with reduced Foxp 2 expression is consistent with the hypothesis that Foxp2 normally acts to repress the transcription of Gadl and is supported by the prior ChIP-chip data (Vernes et al. 2011). Differences in GAD67 expression have been described as a cause for changes in presynaptic GABA content and inhibitory activity (Lau and Murthy 2012). Thus, reduced Foxp2 expression could lead to increased inhibitory drive of D1R-MSNs through increased GABA production. 
a

PND11

PND14

PND17

PND60

Foxp2 $^{++}$
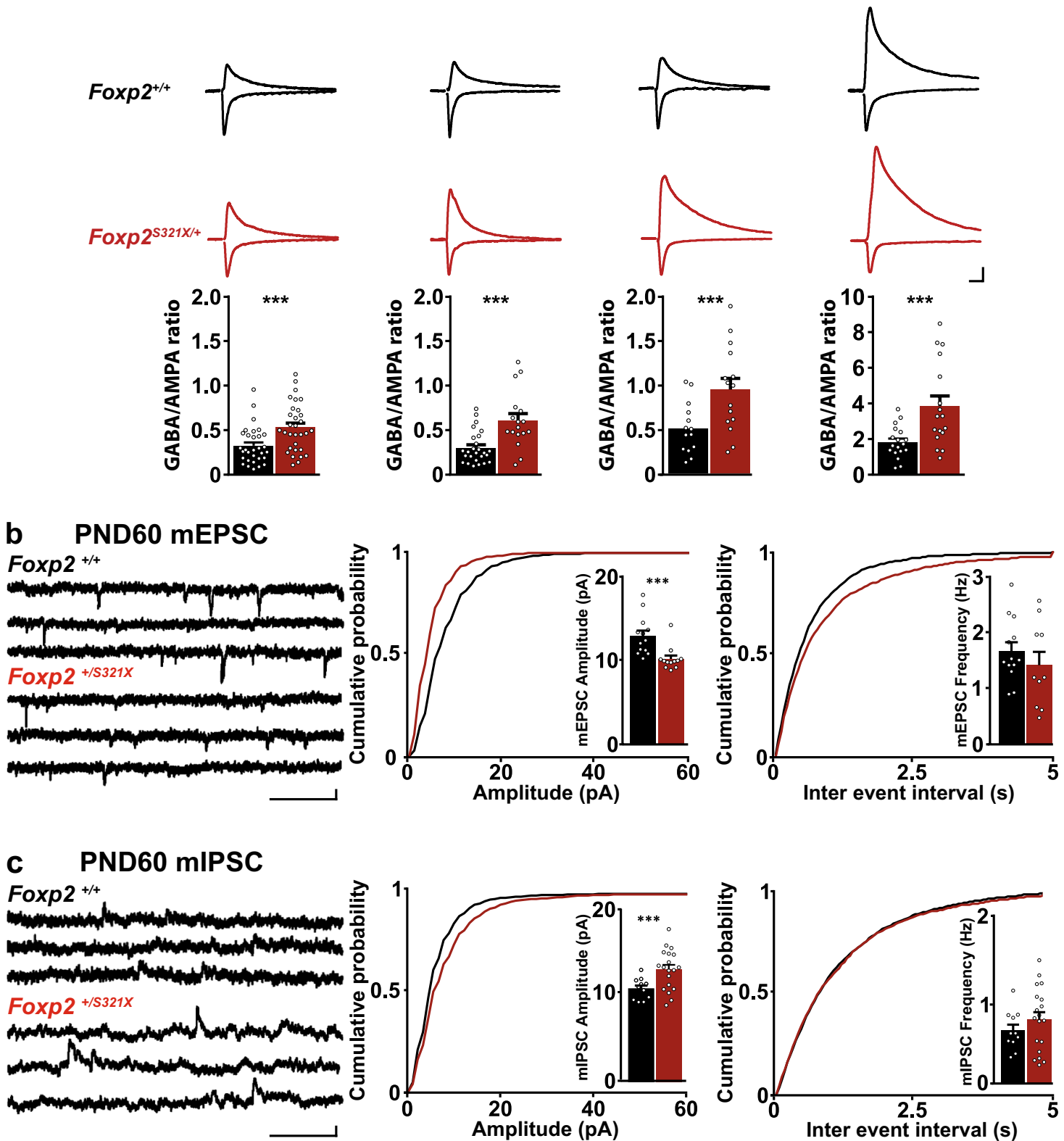

Fig. 2 Decreased excitation and increased inhibition persist in adult mice with decreased Foxp2 expression. a Example traces show AMPA response (negative) and GABA response (positive) in D1RMSNs of Foxp $2^{+/+}$and Foxp $2^{S 32 I X /+}$ mice during development and in adulthood. Scale bar 200/50 pA. GABA/AMPA ratio in D1RMSNs of Foxp2 $2^{+/+}(\mathrm{PND} 11=0.32 \pm 0.037$, PND14 $=0.29 \pm 0.035$, PND17 $=0.50 \pm 0.077, \quad$ PND60 $=2.04 \pm 0.47) \quad$ and $F o x p 2^{S 321 X /+}$ $\left(\right.$ Foxp $^{S 321 X /+} \quad$ PND11 $=0.53 \pm 0.049, \quad$ PND14 $=0.6 \pm 0.078$, PND17 $=0.94 \pm 0.12$, PND60 $=4.5 \pm 0.85)$, mice during development and in adulthood (2-factor ANOVA (genotype $\times$ age $)=P<0.001$ for both factors). $N$ number of mice, $n$ number of cells. Foxp $2^{+/+}$ $N / n=3 / 31$ (PND11), 3/26 (PND13), 3/14 (PND17), 3/18 (PND60), Foxp $2^{S 321 X /+} N / n=3 / 31$ (PND11), 3/26 (PND13), 3/15 (PND17), $3 / 17$ (PND60). b Example traces of mEPSC activity in striatal D1R-
MSNs from adult (PND60) Foxp $2^{+/+}$and Foxp $2^{S 321 X /+}$ mice. Cumulative distribution of mEPSC amplitude $\left(\right.$ Foxp $2^{+/+}=12.9 \pm 0.64 \mathrm{pA}$, Foxp $2^{S 32 I X /+}=10.2 \pm 0.4 \mathrm{pA}, P<0.01$, two-sided Student's $T$ test $)$ and frequency $\left(\right.$ Foxp $2^{+/+}=1.68 \pm 0.16 \mathrm{~Hz}$, Foxp $2^{S 32 I X /+}=1.42 \pm 0.2 \mathrm{~Hz}$, NS, two-sided Student's $T$ test) in striatal D1R-MSNs. Foxp $2^{+/+}$ $N / n=3 / 13, F \operatorname{Foxp} 2^{S 32 I X /+} N / n=3 / 12$. c Example traces of mIPSC activity in striatal D1R-MSNs from adult (PND60) $\mathrm{Foxp}^{+/+}$and Foxp $2^{S 321 X /+}$ mice. Cumulative distribution of mIPSC amplitude $\left(\right.$ Foxp $2^{+/+}=11.36 \pm 0.41 \mathrm{pA}$, Foxp $2^{S 32 I X /+}=12.9 \pm 0.82 \mathrm{pA}, P<0.01$, two-sided Student's $T$ test $)$ and frequency $\left(F o x p 2^{+/+}=0.67 \pm 0.07 \mathrm{~Hz}\right.$, Foxp $2^{S 32 I X /+}=0.81 \pm 0.09 \mathrm{~Hz}, \mathrm{NS}$, two-sided Student's $T$ test) in striatal D1R-MSNs. Foxp $2^{+/+} N / n=4 / 11$, Foxp $2^{S 32 I X /+} N / n=6 / 19$. Scale bar in $\mathbf{b}, \mathbf{c} 200 \mathrm{~ms} / 10 \mathrm{pA}$. $* * * P<0.001$ 
ai
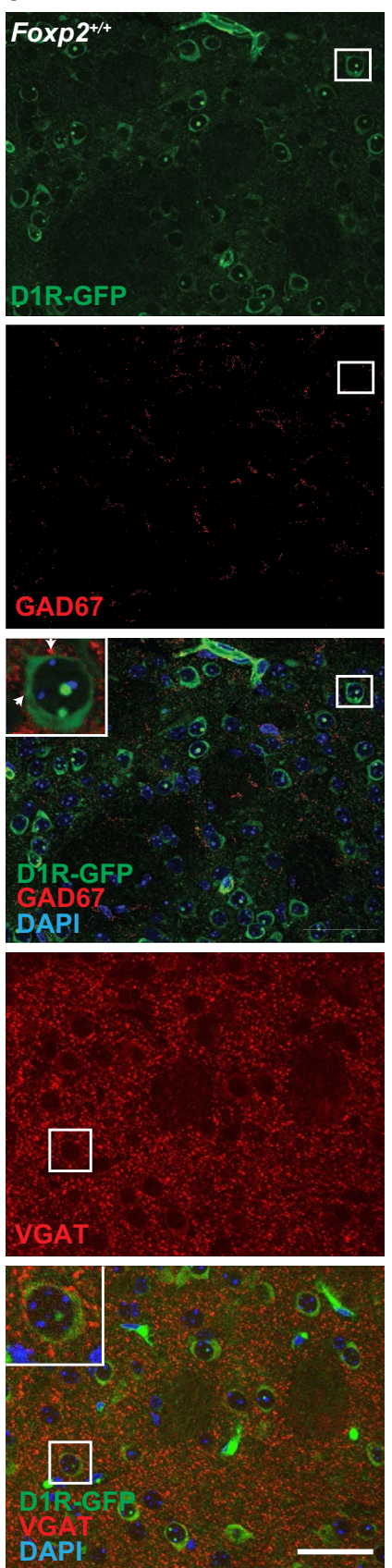

aii
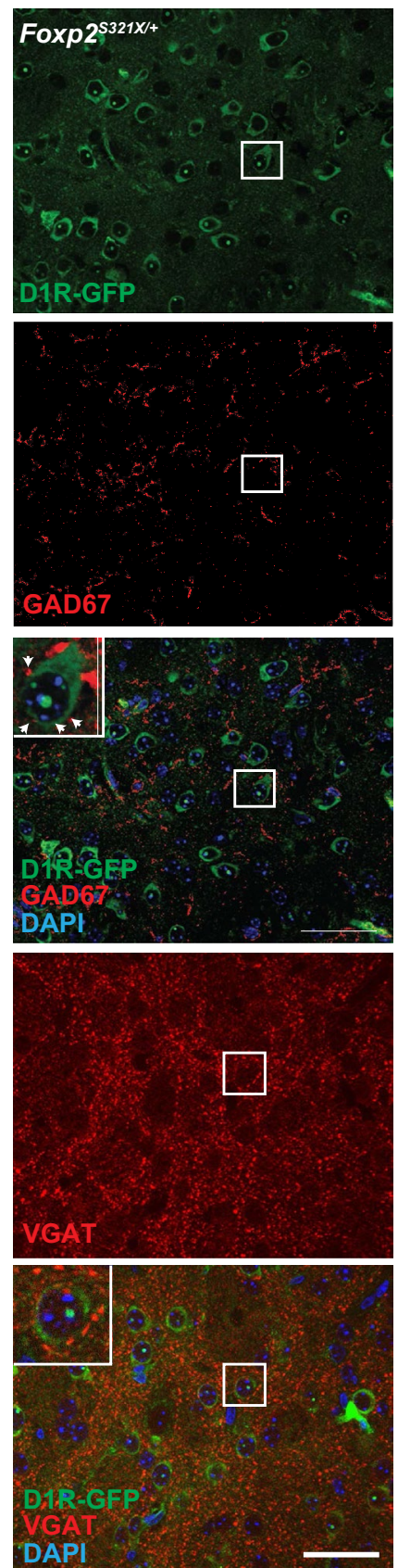

b

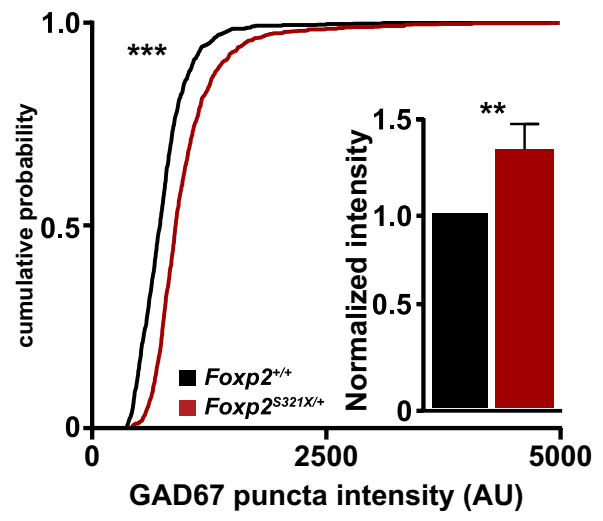

C

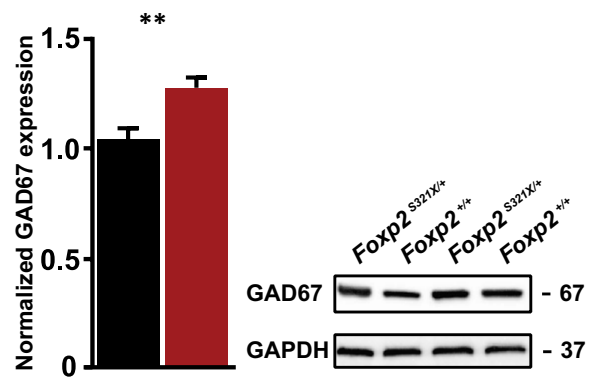

d

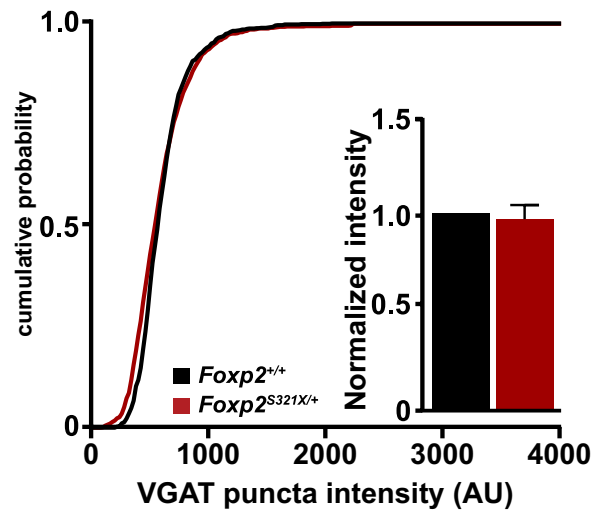

Fig. 3 Increased GAD67 expression in Foxp $2^{S 321 X /+}$ mice (ai, aii). Overview of GAD67 and VGAT expression levels in striatal slices of juvenile (PND10-14) Foxp2 $2^{+/+}$and Foxp2 $2^{S 32 I X /+}$ mice. Insets show puncta which surround D1R-MSN somata. These perisomatic puncta were used for intensity analysis, to restrict analysis to D1R-MSNs. b Comparison of GAD67 expression (both cumulative distribution in arbitrary units (AU) and normalized expression) around D1R-GFP positive somata in dorsolateral striatum of juvenile (PND10-14) Foxp $2^{+/+}$and Foxp $2^{S 32 I X /+}$ mice. All data were compared to normalized expression levels in Foxp $2^{+/+}$mice. (Foxp $2^{S 32 I X /+}$ $1.32 \pm 0.12, \quad P<0.01$, Mann-Whitney $U$ ). Kolmogorov-Smirnov (KS) test was used for the cumulative distribution data, $P<0.001$.
Foxp $^{+/+} N / n=5 / 36$, Foxp $2^{S 32 I X /+} N / n=5 / 36$. c Quantification and representative western blot of GAD67 protein expression in juvenile Foxp $2^{+/+}$and Foxp $2^{S 32 I X /+}$ mice $\left(F o x p 2^{+/+} 1.04 \pm 0.05\right.$, Foxp $2^{S 32 I X /+}$ $1.28 \pm 0.04, P<0.01$, two-sided Student's $T$ test. Foxp $2^{+/+}$and Foxp $2^{S 32 I X /+} N=6$ ). d Comparison of VGAT expression [both cumulative distribution in arbitrary units (AU) and normalized expression] around D1R-GFP positive somata in dorsolateral striatum of juvenile (PND10-14) Foxp2 $2^{+/+}$and Foxp2 $2^{S 32 I X /+}$ mice. Foxp $2^{S 32 I X /+}$ $0.97 \pm 0.07$, NS, Mann-Whitney $U$. KS test for cumulative distribution data: NS. Foxp $2^{+/+} N / n=3 / 12$, Foxp $2^{S 321 X /+} N / n=3 / 12$. $N / n$ : number of animals/number of slices $* P<0.05, * * P<0.01$, $* * * P<0.001$ 


\section{Presynaptic GABA content is increased upon heterozygous loss of Foxp2 function}

As GAD67 levels directly correlate with presynaptic GABA production, we explored if the increased GAD67 levels following reduced Foxp2 expression lead to elevated presynaptic GABA concentration. Presynaptic GABA is stored in vesicles, and is released upon electrical or pharmacological stimulation of the neuron (Alabi and Tsien 2012). A $10 \mathrm{~s} 10 \mathrm{~Hz}$ stimulation protocol has been described that efficiently depletes the entire readily releasable GABA vesicle pool (RRP) (Maas et al. 2017; Chen et al. 2017). This depletion protocol can be used to compare the quantal content of the GABA RRP between D1R-MSNs of wildtype and Foxp $2^{S 321 X /+}$ mice. We show that this stimulation protocol indeed depletes the RRP in juvenile wild-type and Foxp $2^{S 321 X /+}$ mice (Fig. 4a, b). However, in Foxp $2^{S 321 X /+}$ mice the average current transferred per stimulation, as well as the cumulative current transferred after 100 stimulations, was significantly increased compared to wild-type controls (Fig. 4c). However, we did not observe a difference in the kinetics of release when release was normalized, which indicates that vesicle recycling was not affected in Foxp $2^{S 321 X /+}$ mice (Fig. 4b).

Changes in GABA concentration at the synapse can affect synaptic strength and vesicle release probability (Olpe et al. 1994; Jensen et al. 1999). We, therefore, examined both excitatory and inhibitory paired pulse ratios (PPRs) in juvenile Foxp2 $2^{\mathrm{S} 321 \mathrm{X} /+}$ mice and littermate controls. No differences in excitatory PPRs were found between genotypes (Fig. 4d). However, in contrast to the expected increase in inhibitory PPR Foxp $2^{\mathrm{S} 321 \mathrm{X} /+}$ mice showed a lack of inhibitory paired pulse depression, specifically at longer inter stimulus intervals (Fig. 4e). The lack of inhibitory PPD can be explained increased GABA release per stimulation (Fig. 4a). If only a fraction of the total released GABA is necessary to saturate postsynaptic GABA, then reduction of vesicles released with subsequent stimulations would not lead to PPD, because enough GABA is still released to saturate the postsynaptic GABA receptors that are present.

Next, we sought to confirm the increased presynaptic GABA release pharmacologically, to exclude aberrant effects from recurrent stimulation. Local application of $500 \mathrm{mM}$ sucrose for $10 \mathrm{~s}$ (Lipstein et al. 2017) efficiently induced vesicle exocytosis in juvenile Foxp $2^{+/+}$and Foxp $2^{S 321 X /+}$ mice (Fig. 4f). The total current transfer during sucrose application was increased by approximately $50 \%$ in D1R-MSNs from Foxp $2^{S 321 X /+}$ mice, similar to the increase in current transfer observed upon electrical stimulation (Fig. 4f).

Finally, the increase in mIPSC amplitude (Figs. 2b, 3h) in mice with reduced Foxp2 expression also suggests postsynaptic GABA receptor abundance might be increased. We used local application of GABA to investigate if postsynaptic
$\mathrm{GABA}_{\mathrm{A}}$ receptor presence was affected by reduced Foxp2 expression. GABA application elicited a strong response in D1R-MSNs of both Foxp2 $2^{+/+}$and Foxp $2^{S 321 X /+}$ mice (Fig. 4g). No difference in peak response amplitude or total current transfer could be observed between genotypes (Fig. 4g). Taken together, our data suggest that D1R-MSNs exhibit increased GABA content at the presynapse following reduced Foxp2 expression, leading to a heightened quantal GABA release. This in turn leads to elevated inhibition of the striatal direct pathway.

\section{Pharmacological manipulation of inhibition partially rescues motor skill learning deficits in Foxp2 $2^{S 321 X /+}$ mice}

Because aberrant regulation of direct pathway inhibitory activity has been shown to produce motor skill learning deficits (Rothwell et al. 2014; Zhang et al. 2015), we next investigated whether blocking inhibitory activity might be an effective in vivo intervention. One of the most pronounced behavioral deficits displayed by mice with heterozygous mutations in Foxp 2 is decreased motor skill learning, shown by impaired performance on the accelerating rotarod (Groszer et al. 2008; French et al. 2012). Increased inhibition of the direct pathway as demonstrated herein could help explain why Foxp 2 mutations lead to impaired rotarod performance, since successful acquisition of this task is dependent on precise regulation of striatal activity. Cui et al. (2008) showed that increases in presynaptic GABA content cause learning and memory deficits when present in hippocampal neurons. Intriguingly, they found that learning and memory improved dramatically after a low concentration intraperitoneal (IP) injection with picrotoxin (PTX), a compound that blocks $\mathrm{GABA}_{\mathrm{A}}$ receptor mediated inhibition (Cui et al. 2008). We, therefore, hypothesized that a low dose of PTX might be able to ameliorate the motor skill learning deficits present in the Foxp $2^{S 321 X /+}$ mice in a similar manner.

We first validated the presence of motor skill learning deficits in our Foxp $2^{S 321 X /+}$ mice by measuring their performance and learning rate on the accelerating rotarod during five consecutive training days and comparing them to littermate controls (Fig. 5a, b). The impaired rotarod performance in adult Foxp $2^{S 321 X /+}$ mice that we observed is consistent with previous reports on Foxp2 heterozygous mutant mice (French et al. 2012; Groszer et al. 2008). Next, we assessed a viable treatment dose. Injection of $1 \mathrm{mg} / \mathrm{kg}$ PTX produced grand mal seizures in both Foxp $2^{+/+}$and Foxp $2^{S 321 X /+}$ mice, whereas both $0.01 \mathrm{mg} / \mathrm{kg}$ and $0.05 \mathrm{mg} / \mathrm{kg}$ did not have any effect on rotarod performance (Suppl. Figure 3). An intermediate dose of $0.1 \mathrm{mg} /$ $\mathrm{kg}$ did not induce seizures, but had a notable negative effect on the rotarod performance of pre-trained wild-type 


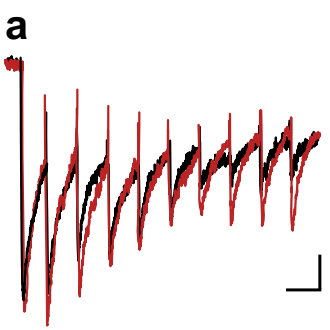

Foxp2 $^{+/+}$ Foxp2 $2^{s 321 X /+}$ b

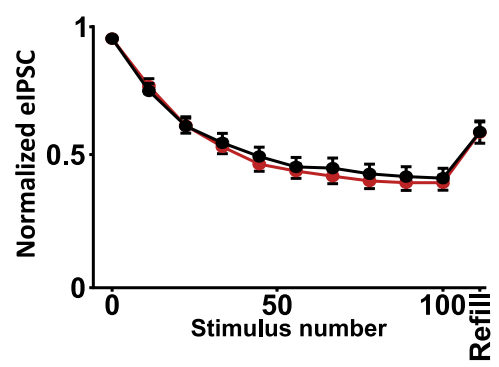

C

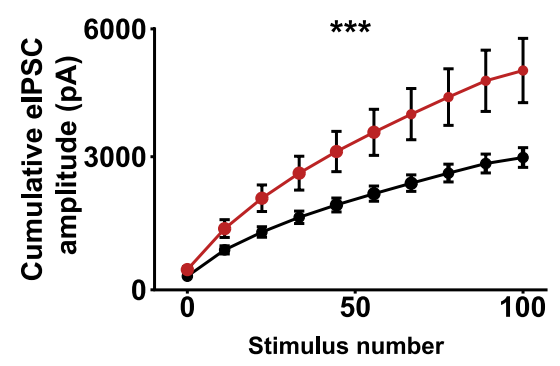

d

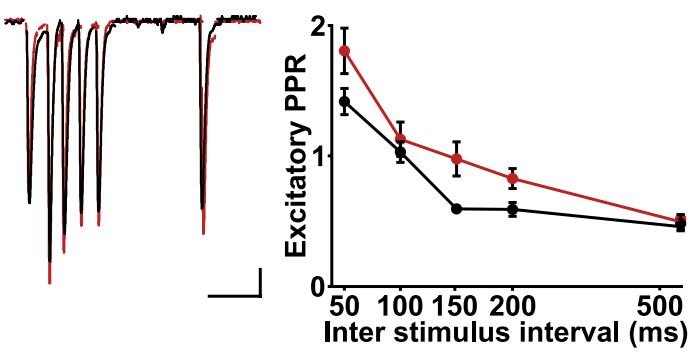

f

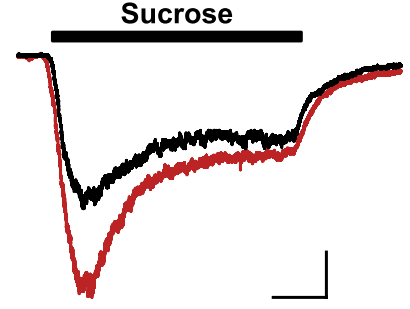

Fig. 4 Presynaptic GABA content in juvenile (PND10-14) striatal D1R-MSNs is increased upon decreased Foxp2 expression. a Example traces of vesicle depletion following train stimulation $(10 \mathrm{~Hz}$, 100 stimuli) in Foxp2 $2^{+/+}$and Foxp2 $2^{S 32 I X /+}$ D1R-MSNs, every 10th response is shown. Scale $100 \mathrm{~ms} / 50 \mathrm{pA}$. b Normalized (to first pulse) IPSC response during train stimulation. c Cumulative IPSC amplitude during train stimulation of D1R MSNs, $\left(\right.$ Foxp $2^{+/+}=$intercept $294.24 \pm 85.3$ pA, cumulative $3112.9 \pm 286.4$ pA, Foxp $2^{S 32 I X /+}=$ intercept $498.9 \pm 301.3 \mathrm{pA}$, cumulative $5142.1 \pm 484.6 \mathrm{pA}, P<0.001$, two-sided Student's $T$ test). $N$ number of mice, $n$ number of cells. Foxp $2^{+/+} N / n=3 / 16$, Foxp $2^{S 321 X /+} N / n=3 / 16$. d Example trace of excitatory PPR at different inter stimulus intervals (ISI) in D1R-MSNs of Foxp $2^{+/+}$and Foxp2 $2^{S 321 X /+}$ mice. Scale $100 \mathrm{~ms} / 50$ pA. Quantification of paired pulse ratio (PPR) $\left(50,100,150,200,500 \mathrm{~ms}\right.$ : Foxp $2^{+/+}$ $1.573 \pm 0.08,1.284 \pm 0.06, \quad 0.958 \pm 0.02,0.955 \pm 0.04,0.856 \pm 0.02$ vs Foxp $2^{S 321 X /+} 1.864 \pm 0.13,1.357 \pm 0.1,1.244 \pm 0.1,1.131 \pm 0.06$, $0.884 \pm 0.04$, NS, Repeated measures ANOVA). Foxp $2^{+/+} N / n=2 / 8$, Foxp $2^{S 321 X /+} N / n=3 / 11$. e Same as d but for inhibitory PPR, (50, 100, 150, 200, 500 ms: Foxp $2^{+/+} 0.936 \pm 0.05,0.872 \pm 0.05$,

mice (Suppl. Figure 4), whereas the rotarod performance of pre-trained heterozygous mice was not affected. e

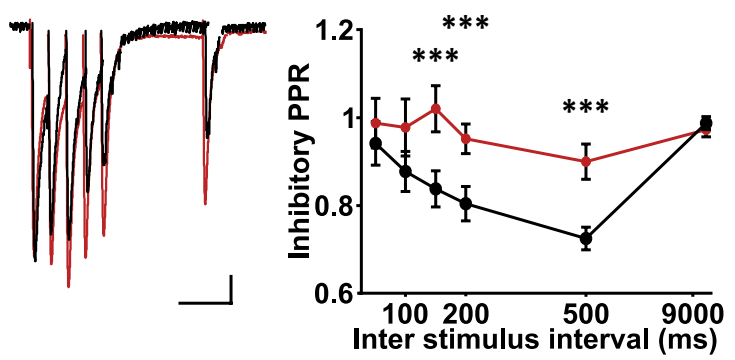

g
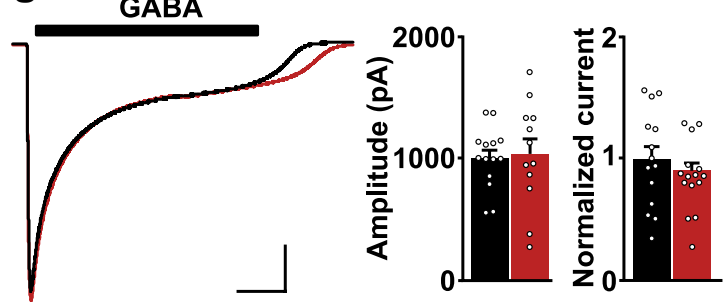

$0.832 \pm 0.04,0.798 \pm 0.04,0.718 \pm 0.03$ vs Foxp $2^{\text {S32IX/+ }} 0.983 \pm 0.06$, $0.973 \pm 0.07,1.016 \pm 0.05,0.947 \pm 0.03,0.894 \pm 0.04 . P<0.001$ for 150, 200, $500 \mathrm{~ms}$, repeated measures ANOVA). Foxp $2^{+/+} \mathrm{N} / n=3 / 23$, Foxp $2^{S 32 I X /+} N / n=3 / 20$. PPR is normalized to the first pulse. f Example trace of postsynaptic inhibitory response to forced vesicle exocytosis during $10 \mathrm{~s}$ local application of $500 \mathrm{mM}$ sucrose. Scale $2 \mathrm{~s} / 50 \mathrm{pA}$. Normalized (to wild-type) current transfer during $10 \mathrm{~s}$ sucrose application $\left(\right.$ Foxp $^{+/+}=9.1 \times 10^{5} \pm 1.26 \times 10^{5}$ pA, $\quad$ Foxp $2^{S 32 I X /+}=13.4 \times$ $10^{5} \pm 1.6 \times 10^{5} \mathrm{pA}, P<0.01$, two-sided Students' $T$ test). Foxp $2^{+/+}$ $N / n=2 / 15$, Foxp $2^{S 32 I X /+} N / n=3 / 16$. g Example trace of postsynaptic response during $10 \mathrm{~s}$ local application of $100 \mu \mathrm{M}$ GABA. Scale $2 \mathrm{~s} / 200 \mathrm{pA}$. Quantification of peak amplitude and total current transfer during GABA application $\left(F o x p 2^{+/+}=1.00 \times 10^{3} \pm 66.7\right.$ pA, Fo $x p 2^{S 32 I X /+}=1.04 \times 10^{3} \pm 125 \mathrm{pA}$, NS, total current transfer Foxp2 $2^{+/}$ ${ }^{+}=4.8 \times 10^{6} \pm 3.4 \times 10^{5} \mathrm{pA}, \quad$ Foxp $2^{S 32 I X /+}=5.4 \times 10^{6} \pm 5.5 \times 10^{5} \mathrm{pA}$, NS, two-sided Student's $T$ test). Foxp $2^{+/+} N / n=2 / 14$, Foxp $2^{\text {S321X/+ }}$ $N / n=2 / 12 . * P<0.05, * * * P<0.001$

We, therefore, injected wild-type and $F o x p 2^{S 321 X /+}$ mice with $0.1 \mathrm{mg} / \mathrm{kg}$ PTX $10 \mathrm{~min}$ prior to each training session and subjected them to the same motor learning paradigm as the vehicle-injected (DMSO) mice. Interestingly, this 

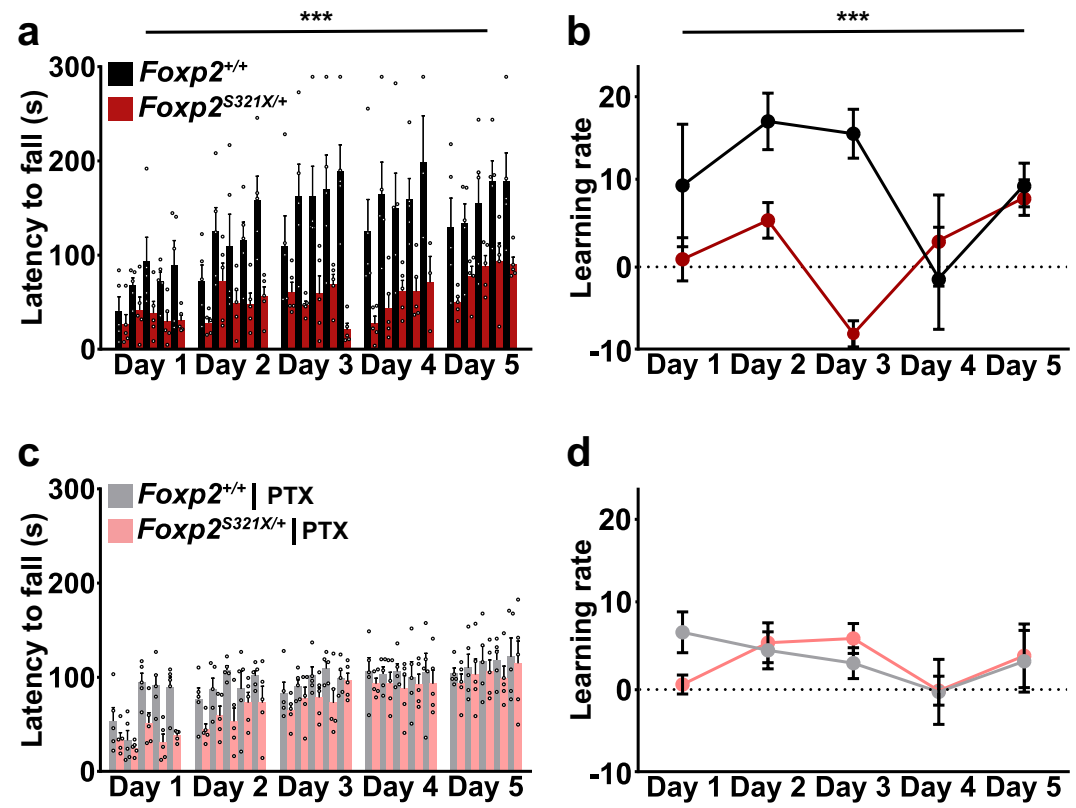

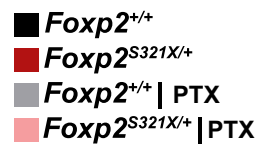

e

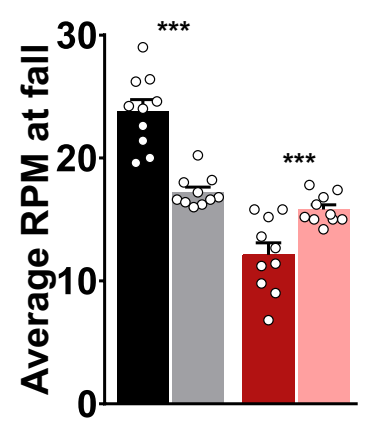

Fig. 5 Pharmacological blockade of inhibition modulates rotarod performance and motor skill learning. a Foxp $2^{S 321 X /+}$ mice show impaired motor skill learning, shown by the decreased latency to fall (in seconds) across training sessions (days 1-5: Foxp $2^{+/+} 75.3 \pm 9.7$, $120.4 \pm 14.4,164.7 \pm 13.6,165.5 \pm 12.2,160.7 \pm 10.8$. Foxp $2^{S 321 X /+}$ $34.4 \pm 3.1,52.5 \pm 7.4,53.1 \pm 8.7,55.0 \pm 8.15,82.6 \pm 8.38 . P<0.01$, repeated measured ANOVA). Each session consists of five trials of $5 \mathrm{~min}$, during which the rotarod accelerated from 4 to $40 \mathrm{rpm}$. b Both Foxp $2^{+/+}$and Foxp $2^{S 321 X /+}$ mice show a positive learning rate during most sessions, with Foxp $2^{+/+}$mice having a significantly higher learning rate (days 1-5: Foxp $2^{+/+}, 10 \pm 7.5,17.8 \pm 3.5,16.3 \pm 3.00$, $-1.4 \pm 6.3,10 \pm 2.7$. Foxp $2^{S 321 X /+}, 0.9 \pm 2.7,5.7 \pm 2.2,-8.2 \pm 1.6$, $3.2 \pm 5.6,8.5 \pm 2.2$. $P<0.05$, repeated measures ANOVA), learning rate was calculated as: Learning rate $=$ latency to fall (session 5-session 1)

$0.1 \mathrm{mg} / \mathrm{kg}$ PTX injection differentially affected rotarod performance of wild-type and Foxp $2^{S 321 X /+}$ mice. Both wild-type and Foxp $2^{\mathrm{S} 321 \mathrm{X} /+}$ mice still show an increase in performance and a positive learning rate during sessions (Fig. 5c, d). Treatment with PTX had a profound negative effect on rotarod performance in Foxp $2^{+/+}$mice, whilst in Foxp $2^{S 321 X /+}$ mice, rotarod performance was significantly increased compared to mice without treatment. These opposite effects of PTX treatment resulted in a comparable performance of Foxp $2^{+/+}$and Foxp $2^{S 321 X /+}$ mice when comparing average rotarod speed (RPM) at fall from the last two trials, (Fig. 5e) with PTX treatment. This shows that decreasing inhibitory activity might be a viable method to ameliorate motor deficits induced by decreased expression of Foxp2 and corroborates our data that in mice with reduced Foxp2 expression the E/I balance is shifted towards increased inhibition. c, d Foxp $2^{+/+}$mice subjected to $0.1 \mathrm{mg} / \mathrm{kg}$ intraperitoneal injection of PTX show decreased rotarod performance and learning rates, whereas these were increased in Foxp $2^{S 321 X /+}$ mice (latency to fall: days 1-5: Foxp $2^{+/+} 71.7 \pm 12.4,91.7 \pm 5.5,96.4 \pm 4.7,104.4 \pm 1.2$, $114 \pm 3.2$. Foxp $2^{S 321 X /+} 33.8 \pm 4.5,59.8 \pm 5.7,77.4 \pm 5.3,91.8 \pm 1.1$, 103.2 \pm 3.61. NS learning rate: Foxp $2^{+/+} 7.2 \pm 2.5,5 \pm 2.3,3.4 \pm 1.9$, $-0.1 \pm 4.0,3.6 \pm 3.8$. Foxp $2^{S 32 I X /+}, 0.76 \pm 1.2,5.9 \pm 2.5,6.4 \pm 1.9$, $0.0 \pm 1.8,4.3 \pm 3.9$. NS, repeated measures ANOVA). e Average RPM at which mice fail the accelerating rotarod task during session 4 and 5 in vehicle and PTX conditions (vehicle, Foxp $2^{+/+} 24.1 \pm 0.94$ RPM, Foxp $2^{\text {S32IX/+ }} 12 \pm 0.96$ RPM, $P<0.001$. PTX, Foxp $2^{+/+} 16.7 \pm 0.4$ RPM, Foxp $2^{S 32 I X+} 15.3 \pm 0.372$ RPM, NS, two-sided Students' $T$ test). For all treatment conditions, $N=5$ mice. $* * * P<0.001$

\section{Discussion}

Mutations in FoxP2 affect striatal circuitry both in human cases of speech/language disorder and in animal models of Foxp2 dysfunction (Liegeois et al. 2003; Schulz et al. 2010; Groszer et al. 2008; French et al. 2012). Here, we show that Foxp 2 affects both excitatory and inhibitory striatal activity in a cell-specific manner during development and in adulthood. Foxp2 is predominantly expressed in striatal direct pathway D1R-MSNs. Decreased Foxp2 expression leads to reduced excitatory activity and increased inhibitory activity in D1R-MSNs. Molecular evidence suggests that the increase in inhibitory activity is due to a de-repression of GAD67 expression. The number of GAD67-positive puncta around the somata of D1R-MSNs increases when Foxp2 expression is reduced, which is accompanied by increased presynaptic GABA content and increased inhibition of the striatal direct pathway. Intriguingly, blocking inhibition with 
PTX results in a partial rescue of motor skill learning deficits in Foxp $2^{S 321 X /+}$ mice, whereas wild-type littermates show impaired motor skill learning after treatment.

Striatal excitatory connections are formed exclusively by projections from external sources (Hunnicutt et al. 2016). Subpopulations of cortical and thalamic projection neurons form excitatory connections to the striatum (Pan et al. 2010; Hintiryan et al. 2016), and these brain regions contain Foxp2-positive cells as well (Lai et al. 2003; Takahashi et al. 2003; Vargha-Khadem et al. 2005; Hisaoka et al. 2010; Sia et al. 2013). However, it is currently unknown if the cortical and thalamic neurons that express Foxp2 project to the striatum. Our data show that reduced Foxp2 expression decreases D1R-MSN mEPSC amplitude, without influencing mEPSC frequency or excitatory PPR. This suggests that only postsynaptic excitatory strength is affected, and excitatory inputs to the striatum are not affected by reduced Foxp2 expression. Furthermore, the lack of excitatory presynaptic changes in striatal MSNs indicates that excitatory cortical and thalamic cells which do express Foxp2 either do not project to MSNs in the dorsolateral striatum or that Foxp2 has no presynaptic function in these neurons.

Concurrent with the decrease in excitatory activity, we observed an increase in inhibitory activity of striatal D1R-MSNs. Gene ontology analysis following Foxp2ChIP experiments (Vernes et al. 2011), which groups significantly regulated genes among common biological pathways, has suggested GABA signaling pathways are regulated by Foxp2. Striatal MSNs express both GAD67 and GAD65, two catalytic enzymes involved in the production of GABA (Laprade and Soghomonian 1999). To our knowledge, GAD65 has not been identified as a regulatory target of Foxp2, and mRNA levels of Gad2 (the gene which codes for GAD65) are unaltered when Foxp2 expression is reduced (French et al. 2007). In contrast, the Gadl gene is clearly a regulatory target of Foxp2, shown by ChIP (Vernes et al. 2011), and we show that expression of its protein product GAD67 is increased around striatal D1RMSNs of Foxp $2^{S 321 X /+}$ mice. The direct regulation of Gadl by Foxp2 suggests Foxp2 expression is necessary to regulate GAD67 levels in the striatum. However, we cannot rule out that GAD67 levels might be altered in striatal interneurons through non-cell autonomous mechanisms dependent on Foxp2. Interestingly, increased GAD67 expression levels have been causally linked to increased presynaptic GABA content (Chao et al. 2010; Hibbert et al. 2004) and enhanced GABA transmission (Krishnan et al. 2015), both of which occur in D1R-MSNs from Foxp $2^{S 321 X /+}$ mice.

Spine formation and excitatory activity in striatal MSNs are affected in homozygous Foxp2 knockout mice during early postnatal development, possibly through increased Mef2C expression. Mef2C is a transcription factor, which acts as a developmental brake on glutamatergic synapse formation and is regulated by Foxp2 (Chen et al. 2016). However, we show that decreased excitatory activity in D1R-MSNs is present in both juvenile and adult Foxp $2^{S 32 I X /+}$ mice. Mef2C expression is virtually absent in adolescent mouse striatum (Chen et al. 2016). This suggests that the decrease in excitatory activity could be caused by impaired generation of glutamatergic synapses during early development, which can have lasting effects on physiology and behavior in adult mice (Harrington et al. 2016). Intriguingly, Mef2C, has been shown to regulate the activity of both excitatory and inhibitory synapses in cortex in a cell-autonomous way (Harrington et al. 2016). Knockout of Mef $2 C$ decreased excitation and increased inhibition in cortex, similar to the physiological changes that we show in striatal D1R-MSNs of Foxp $2^{S 321 X /+}$ mice. Dysregulation of striatal Mef2C expression following heterozygous Foxp2 loss of function could, therefore, be partially responsible for the striatal E/I imbalance that we measured.

Our findings show that reduced Foxp2 expression disrupts striatal E/I balance, which is dynamically regulated through pre-and postsynaptic mechanisms (Abbott and Nelson 2000; Bolshakov and Siegelbaum 1994; Bi and Poo 1998; Yang and Calakos 2013). Whilst the decreased excitatory activity seems to originate postsynaptically, our data suggest that reduced Foxp2 expression leads to increased presynaptic GABA production. D1R-MSNs form extensive connections toward the substantia nigra (SN), such that reduced activation of D1R-MSNs leads to reduced inhibition of the SN. Increased release of GABA could be a cell-autonomous mechanism to increase the inhibitory drive of D1R-MSN projections toward the SN. However, intra-striatal inhibition is governed by MSNs as well: D1R-MSNs project to other D1R-MSNs (Taverna et al. 2008). This means that a feedback loop could occur to increase inhibitory drive, which would result in stronger inhibition of striatal D1RMSNs. Paired recording of striatal D1R-MSNs in Foxp2 $2^{+/+}$ and Foxp $2^{S 321 X /+}$ could help to determine whether such a feedback loop is present and if such a mechanism can negate the effect of the increased presynaptic GABA production in presynaptic terminals within the $\mathrm{SN}$.

Furthermore, the striatal E/I imbalance following reduced Foxp2 expression is maintained throughout development and in adult mice. This can explain why impaired striatal plasticity and motor skill learning deficits are present in adult mice with heterozygous Foxp2 mutations (French et al. 2012; Groszer et al. 2008). Interestingly, in a mouse model for neuroligin-3 (NL-3) dysfunction, known to produce similar behavioral and physiological phenotypes as mutation of Foxp2, adult re-expression of NL-3 rescues motor skill learning deficits (Rothwell et al. 2014). Restoration of E/I balance in adulthood could, therefore, be a viable strategy to ameliorate the motor learning deficits observed upon reduced Foxp2 expression. Modulation of GABAergic activity using 
$\mathrm{GABA}_{\mathrm{A}}$ antagonists has been shown to improve learning and memory in mouse models for cognitive disorders (Rueda et al. 2008; Cui et al. 2008) and phase I clinical trials are underway to test $\mathrm{GABA}_{\mathrm{A}}$ antagonists on people with Down syndrome (Contestabile et al. 2017). We show that modulation of GABAergic activity by partially blocking inhibitory activity increases motor skill learning in Foxp $2^{S 321 X /+}$ mice. Intriguingly, wild-type mice were adversely affected by the same PTX treatment, which indicates that successful modulation of GABAergic activity might be highly dose dependent.

Taken together, we show for the first time that reduced Foxp2 expression bidirectionally affects both excitatory and inhibitory activity of striatal direct pathway MSNs, throughout development as well as in adult mice. Partially blocking inhibitory activity in vivo might restore this E/I imbalance, and we found that this intervention had a positive effect on motor skill learning in mice with reduced Foxp2 expression. Restoring the E/I balance by pharmacologically modulating inhibitory activity might be a feasible therapeutic intervention for complex motor disorders.

\section{Materials and methods}

\section{Mouse lines}

The experimental procedures were approved by the Animal Ethics Committee of the Radboud University Nijmegen, under DEC application number 2014-098 (Nijmegen, The Netherlands) and conducted in accordance with the Dutch legislation. Every effort was made to minimize animal discomfort and the number of animals used.

The Foxp2-S321X line was maintained on a C57BL/6J background, and heterozygotes and wildtype littermates between PND11 and PND17 (juvenile) or PND55-65 (adult) were used for the immunofluorescent stainings and electrophysiological recordings. The generation, markerassisted backcrossing and genotyping of this strain are fully described in (Groszer et al. 2008; Keays et al. 2006; Coghill et al. 2002). BACtrap mice carrying GFP under the D1R promoter (D1R-GFP) or D2R promoter (D2R-GFP) were originally generated by the GENSAT (Gene Expression Nervous System Atlas) (Gong et al. 2003) and backcrossed to C57BL6/J mice.

\section{Electrophysiology}

Experiments were conducted on $350 \mu \mathrm{m}$ thick coronal slices. Mice (PND11-17 or PND55-65) were sacrificed by decapitation following isoflurane anesthesia. Slices were cut using a vibratome (HM650V Thermo Scientific) in cooled $\left(4^{\circ} \mathrm{C}\right)$ artificial cerebrospinal fluid containing (in $\mathrm{mM}$ ): $87 \mathrm{NaCl}$, 11 Glucose, 75 Sucrose, $2.5 \mathrm{KCl}, 1.25 \mathrm{NaH}_{2} \mathrm{PO}_{4}, 0.5 \mathrm{CaCl}_{2}$,
$7 \mathrm{MgCl}_{2}, 26 \mathrm{NaHCO}_{3}$, continuously oxygenated with $95 \%$ $\mathrm{O}_{2} / 5 \% \mathrm{CO}_{2}$. Collection of slices started when the striatum became visible and slices were collected until the hippocampus was visible. After collection, slices were incubated at $32{ }^{\circ} \mathrm{C}$ in oxygenated ACSF for at least $1 \mathrm{~h}$ before recording. Slices were transferred to the recording setup $10 \mathrm{~min}$ prior to recording and incubated in recording ACSF containing (in mM): $124 \mathrm{NaCl}, 3 \mathrm{KCl}, 1.25 \mathrm{NaH}_{2} \mathrm{PO}_{4}, 2 \mathrm{CaCl}_{2}, 1$ $\mathrm{MgCl}_{2}, 26 \mathrm{NaHCO}_{3}, 10$ Glucose, continuously oxygenated and heated to $32{ }^{\circ} \mathrm{C}$. Patch pipettes (3.5-5.5 M $)$ ) were made from borosilicate glass capillaries and filled with intracellular solution containing: $115 \mathrm{CsMeSO}_{3} ; 10 \mathrm{CsCl} ; 10 \mathrm{HEPES}$; 2.5 $\mathrm{MgCl}_{2} ; 4 \mathrm{Na} 2 \mathrm{ATP} ; 0.4 \mathrm{NaGTP} ; 10 \mathrm{Na}$-Phosphocreatine; 0.6 EGTA, 10 QX-314. Activity was recorded using a Digidata 1440A digitizer and a Multiclamp 700B amplifier (Molecular Devices). Sampling rate was set at $20 \mathrm{kHz}$ and a lowpass $1 \mathrm{kHz}$ filter was used during recording. All recordings were conducted in the dorsolateral quadrant of the striatum.

\section{Miniature postsynaptic currents}

mEPSCs were recorded in the prescience of Tetrodotoxin (TTX, $1 \mu \mathrm{M}$, Tocris) and Picrotoxin (PTX, $100 \mu \mathrm{M}$, Tocris) at a holding voltage of $-60 \mathrm{mV}$. mIPSCs were recorded in the presence of Tetrodotoxin (TTX, $1 \mu \mathrm{M}$, Tocris), 6-cyano7-nitroquinoxaline-2,3-dione (CNQX, $5 \mu \mathrm{M}$, Tocris) and (2R)-amino-5-phosphonovaleric acid (APV, $100 \mu \mathrm{M}$, Tocris) at a holding voltage of $+10 \mathrm{mV}$.

\section{GABA/AMPA ratio}

All stimulation experiments were conducted by stimulation of afferent corticostriatal and intrastriatal axons using a bipolar concentric stimulus electrode (FHC, Bowdoin, Maine) placed in the dorsolateral striatum. GABA/AMPA ratio was measured in the presence of APV $(100 \mu \mathrm{M})$. Cells were voltage-clamped at $-60 \mathrm{mV}$ and a $1 \mathrm{~ms}$ stimulus from a bipolar tungsten electrode was given to record the AMPA response. Subsequently cells were clamped at $0 \mathrm{mV}$ and the GABA response was measured.

\section{Paired pulse ratio}

Excitatory PPR was measured in the presence of PTX $(100 \mu \mathrm{M})$ and APV $(100 \mu \mathrm{M})$ with voltage clamped at $-60 \mathrm{mV}$. Inhibitory PPR was measured in the presence of CNQX $(5 \mu \mathrm{M})$ and APV $(100 \mu \mathrm{M})$ with voltage clamped at $-60 \mathrm{mV}$. Stimulation strength was set to evoke an approximately $200 \mathrm{pA}$ response to the first stimulus. Two $1 \mathrm{~ms}$ pulses were given with a $50 \mathrm{~ms}, 100 \mathrm{~ms}, 150 \mathrm{~ms}, 200 \mathrm{~ms}$, $500 \mathrm{~ms}$ or $9000 \mathrm{~ms}$ (inhibitory PPR only) interval. PPR was 
calculated as the peak 2/peak 1 ratio after correcting for any residual current at the second pulse.

\section{GABA vesicle depletion}

One millisecond pulses were given at $10 \mathrm{~Hz}$ for $10 \mathrm{~s}$ to entirely deplete the presynaptic GABA vesicle pool. After each $10 \mathrm{~s}$ stimulus train, cells were given $0.2 \mathrm{~Hz}$ stimulations for $40 \mathrm{~s}$ to assess the recovery of the vesicle pool between each stimulus train. One recording consisted of 10 consecutive stimulus trains. Cells were recorded in the presence of CNQX and at a holding voltage of $-60 \mathrm{mV}$.

\section{Compound application}

Sucrose $(500 \mathrm{mM})$ or GABA $(20 \mu \mathrm{M})$ was applied using a pressure ejection system (PDES-2DX, NPI, Tamm, Germany). The injection pressure was set to $5 \mathrm{psi} / 0.4 \mathrm{bar}$ and injection duration was set to $10 \mathrm{~s}$. Interinjection interval was set to $1 \mathrm{~min}$. Compounds were delivered using a micropipette positioned at $30 \mu \mathrm{m}$ from the target cell soma.

\section{Immunofluorescence}

Animals were sacrificed by decapitation and whole mouse brain was fixed in $4 \%$ paraformaldehyde (PFA) $/ 4 \%$ sucrose for $24 \mathrm{~h} .60 \mu \mathrm{m}$ coronal sections including the striatum were cut using a vibratome (Leica VT1000S, Leica microsystems). Slices were transferred to $1 \mathrm{x}$ Phosphate buffered saline (PBS) for immunofluorescent staining. The following antibodies were used: FoxP2 (Santa Cruz Sc-21069, 1:500), GAD67 (Millipore MAB5406, 1:200). Imaging was done using a Zeiss upright fluorescent microscope with apotome (Zeiss Axio Images, Oberkochen, Germany) using a $63 \times$ oil immersion objective. For subsequent analysis of immunofluorescent staining, at least four slices per animal were analyzed. Data were normalized and average values for each animal were taken as the independent variable for further statistical analysis. Images were analyzed offline using FIJI (Fiji is just imageJ) image analysis software.

\section{Intraperitoneal injection}

Foxp $2^{S 321 X /+}$ mice and wild-type littermate controls were injected intraperitoneally with either vehicle (DMSO) or $0.1 \mathrm{mg} / \mathrm{kg}$ picrotoxin (Tocris, Bristol, UK). Injection was done by hand and mice were placed back in their home cage for 10 min following injection, after which mice were placed on the accelerating rotarod.

\section{Accelerating rotarod}

Foxp $2^{S 321 X /+}$ mice (6-8 weeks old) and wild-type littermate controls were placed on an accelerating rotarod (LE8200, Harvard apparatus) which increased rotation speed from 4 to 40 r.p.m. over a 5-min period. Mice were trained for five consecutive days, with five trials per day. Latency to fall (in seconds or RPM at fall) was scored, and mice were placed back in their home cage for 5 min between trials.

\section{Western blot}

PND10-15 Foxp $2^{S 321 X /+}$ animals and wild-type controls were sacrificed by decapitation. The striatum was dissected from separated hemispheres, frozen in liquid nitrogen and kept at $-80{ }^{\circ} \mathrm{C}$. Samples were homogenized in $200 \mu \mathrm{l}$ of lysis buffer (50 mM Hepes pH 7.4, $140 \mathrm{mM} \mathrm{NaCl}, 0.1 \%$ Triton-X100, 1\% Tween 20, 0.1\% deoxycholate) containing protease inhibitor mix (Roche Diagnostics). Protein levels were assessed using BCA. Sodium dodecyl sulfate polyacrylamide gel electrophoresis (SDS-PAGE) on $10 \%(\mathrm{w} / \mathrm{v}$ ) at $200 \mathrm{~V}$ for $30 \mathrm{~min}$ was carried out using a Mini-Protean system (Bio-Rad, USA). Protein $(50 \mu \mathrm{g})$ was loaded in each lane with loading buffer $(0.25 \mathrm{M}$ Tris-HCl, $\mathrm{pH} 6.8,2 \%$ SDS, $10 \%$ glycerol, $0.25 \%$ bromophenolblue, $4 \%$ beta-mercaptoethanol). After electrophoresis, proteins were transferred to a polyvinylidene fluoride membrane (PVDF, Amersham, Hybond-P), using an electrophoretic transfer system (BioRad, USA). The membranes were then blocked with 5\% skimmed milk dissolved in TBS-tween $0.1 \%$ for $1 \mathrm{~h}$. The membranes were incubated overnight at $4{ }^{\circ} \mathrm{C}$ with the primary antibodies diluted in blocking buffer containing $1 \%$ skimmed milk dissolved in a TBS-Tween. The primary antibodies were the following: mouse monoclonal anti-bodies GAD67 (1:1000, Abcam), and GAPDH as a control (1:1000, cell signaling). After being washed for $1 \mathrm{~h}$ with $1 \%$ skimmed milk in TBS-T $(0.05 \%)$, the membranes were incubated for $1 \mathrm{~h}$ in the dark at room temperature with goat-anti-mouse secondary antibody (1:5000; Bio-Rad, Goat-anti-mouse HRP conjugated). The membranes were imaged using a Chemidoc Touch imaging system (Bio-rad, Hercules, CA) and the generated pictures were quantified using ImageJ software. The levels of protein expression were normalized to GAPDH. Protein expression values are normalized to Foxp $2^{+/+}$expression (relative intensity).

\section{Statistics}

Sample size was calculated assuming power of 0.8 and effect size $d=0.8$, data are acquired from at least three mice for each genotype. All data are shown as mean \pm SEM. Analysis between two groups was done using Students' $T$ test when normally distributed, or Mann-Whitney $U$ rank-sum analysis 
when data did not pass normality. Analysis between multiple groups using repeated measures ANOVA. All statistical analysis was conducted in PRISM (Graphpad PRISM 7.00, Graphpad Software, San Diego, CA).

Acknowledgements We thank Nathaniel Heintz and Myriam Heiman for kindly providing D1R-GFP and D2R-GFP BACtrap mice. We are grateful to Pelagia Deriziotis for backcrossing of the mouse lines used for this study. JRvR is supported by an RUMC Junior Round grant from the Donders institute Ph.D. program, awarded to NNK and SCV. SCV is supported by a Marie Curie Career Integration Grant (PCIG12GA-2012-333978) and by a Max Planck Research Group Award. SEF is supported by the Max Planck Society.

Author contributions SCV, NNK conceived and supervised the study; SCV, NNK and SEF provided resources; JRvR, SCV, NNK designed the experiments; JRvR performed all experiments; JRvR, SEF, SCV, NNK wrote the manuscript.

\section{Compliance with ethical standards}

Conflict of interest The authors declare no competing financial interests,

Human and animal rights The experimental animal procedures were approved by the Animal Ethics Committee of the Radboud University Nijmegen, under DEC application number 2014-098 (Nijmegen, the Netherlands) and conducted in accordance with the Dutch legislation. Every effort was made to minimize animal discomfort and the number of animals used. No human participants were used in this study.

Open Access This article is distributed under the terms of the Creative Commons Attribution 4.0 International License (http://creativeco mmons.org/licenses/by/4.0/), which permits unrestricted use, distribution, and reproduction in any medium, provided you give appropriate credit to the original author(s) and the source, provide a link to the Creative Commons license, and indicate if changes were made.

\section{References}

Abbott LF, Nelson SB (2000) Synaptic plasticity: taming the beast. Nat Neurosci 3(Suppl):1178-1183. https://doi.org/10.1038/81453 Alabi AA, Tsien RW (2012) Synaptic vesicle pools and dynamics. Cold Spring Harb Perspect Biol 4(8):a013680. https://doi.org/10.1101/ cshperspect.a013680

Bi GQ, Poo MM (1998) Synaptic modifications in cultured hippocampal neurons: dependence on spike timing, synaptic strength, and postsynaptic cell type. J Neurosci 18(24):10464-10472

Bolshakov VY, Siegelbaum SA (1994) Postsynaptic induction and presynaptic expression of hippocampal long-term depression. Science 264(5162):1148-1152

Calabresi P, Picconi B, Tozzi A, Ghiglieri V, Di Filippo M (2014) Direct and indirect pathways of basal ganglia: a critical reappraisal. Nat Neurosci 17(8):1022-1030. https://doi.org/10.1038/ nn. 3743

Chao HT, Chen H, Samaco RC, Xue M, Chahrour M, Yoo J, Neul JL, Gong S, Lu HC, Heintz N, Ekker M, Rubenstein JL, Noebels JL, Rosenmund C, Zoghbi HY (2010) Dysfunction in GABA signalling mediates autism-like stereotypies and Rett syndrome phenotypes. Nature 468(7321):263-269. https://doi.org/10.1038/ nature 09582

Chen YC, Kuo HY, Bornschein U, Takahashi H, Chen SY, Lu KM, Yang HY, Chen GM, Lin JR, Lee YH, Chou YC, Cheng SJ, Chien CT, Enard W, Hevers W, Paabo S, Graybiel AM, Liu FC (2016) Foxp2 controls synaptic wiring of corticostriatal circuits and vocal communication by opposing Mef2c. Nat Neurosci 19(11):15131522. https://doi.org/10.1038/nn. 4380

Chen AI, Satterfield R, Young SM Jr, Jonas P (2017) Synaptotagmin 2 is the fast $\mathrm{Ca}^{2+}$ sensor at a central inhibitory synapse. Cell Rep 18(3):723-736. https://doi.org/10.1016/j.celrep.2016.12.067

Chiu YC, Li MY, Liu YH, Ding JY, Yu JY, Wang TW (2014) Foxp2 regulates neuronal differentiation and neuronal subtype specification. Dev Neurobiol 74(7):723-738. https://doi.org/10.1002/ dneu.22166

Coghill EL, Hugill A, Parkinson N, Davison C, Glenister P, Clements S, Hunter J, Cox RD, Brown SD (2002) A gene-driven approach to the identification of ENU mutants in the mouse. Nat Genet 30(3):255-256. https://doi.org/10.1038/ng847

Contestabile A, Magara S, Cancedda L (2017) The GABAergic hypothesis for cognitive disabilities in down syndrome. Front Cell Neurosci 11:54. https://doi.org/10.3389/fncel.2017.00054

Cui Y, Costa RM, Murphy GG, Elgersma Y, Zhu Y, Gutmann DH, Parada LF, Mody I, Silva AJ (2008) Neurofibromin regulation of ERK signaling modulates GABA release and learning. Cell 135(3):549-560. https://doi.org/10.1016/j.cell.2008.09.060

Dehorter N, Michel FJ, Marissal T, Rotrou Y, Matrot B, Lopez C, Humphries MD, Hammond C (2011) Onset of pup locomotion coincides with loss of NR2C/D-mediated cortico-striatal epscs and dampening of striatal network immature activity. Front Cell Neurosci 5:24. https://doi.org/10.3389/fncel.2011.00024

Devanna P, Middelbeek J, Vernes SC (2014) FOXP2 drives neuronal differentiation by interacting with retinoic acid signaling pathways. Front Cell Neurosci 8:305. https://doi.org/10.3389/fncel .2014 .00305

Doyle JP, Dougherty JD, Heiman M, Schmidt EF, Stevens TR, Ma G, Bupp S, Shrestha P, Shah RD, Doughty ML, Gong S, Greengard P, Heintz N (2008) Application of a translational profiling approach for the comparative analysis of CNS cell types. Cell 135(4):749 762. https://doi.org/10.1016/j.cell.2008.10.029

Enard W, Gehre S, Hammerschmidt K, Holter SM, Blass T, Somel M, Bruckner MK, Schreiweis C, Winter C, Sohr R, Becker L, Wiebe V, Nickel B, Giger T, Muller U, Groszer M, Adler T, Aguilar A, Bolle I, Calzada-Wack J, Dalke C, Ehrhardt N, Favor J, Fuchs H, Gailus-Durner V, Hans W, Holzlwimmer G, Javaheri A, Kalaydjiev S, Kallnik M, Kling E, Kunder S, Mossbrugger I, Naton B, Racz I, Rathkolb B, Rozman J, Schrewe A, Busch DH, Graw J, Ivandic B, Klingenspor M, Klopstock T, Ollert M, QuintanillaMartinez L, Schulz H, Wolf E, Wurst W, Zimmer A, Fisher SE, Morgenstern R, Arendt T, de Angelis MH, Fischer J, Schwarz J, Paabo S (2009) A humanized version of Foxp2 affects corticobasal ganglia circuits in mice. Cell 137(5):961-971. https://doi. org/10.1016/j.cell.2009.03.041

Ferland RJ, Cherry TJ, Preware PO, Morrisey EE, Walsh CA (2003) Characterization of Foxp2 and Foxp1 mRNA and protein in the developing and mature brain. J Comp Neurol 460(2):266-279. https://doi.org/10.1002/cne.10654

Fong WL, Kuo H-Y, Wu H-L, Chen S-Y, Liu F-C (2018) Differential and overlapping pattern of Foxp1 and Foxp2 expression in the striatum of adult mouse brain. Neuroscience 388:214-223

French CA, Groszer M, Preece C, Coupe AM, Rajewsky K, Fisher SE (2007) Generation of mice with a conditional Foxp2 null allele. Genesis 45(7):440-446. https://doi.org/10.1002/dvg.20305

French CA, Jin X, Campbell TG, Gerfen E, Groszer M, Fisher SE, Costa RM (2012) An aetiological Foxp2 mutation causes aberrant striatal activity and alters plasticity during skill learning. 
Mol Psychiatry 17(11):1077-1085. https://doi.org/10.1038/ mp.2011.105

Fujita E, Tanabe Y, Shiota A, Ueda M, Suwa K, Momoi MY, Momoi $\mathrm{T}$ (2008) Ultrasonic vocalization impairment of Foxp2 (R552H) knockin mice related to speech-language disorder and abnormality of Purkinje cells. Proc Natl Acad Sci USA 105(8):3117-3122. https://doi.org/10.1073/pnas.0712298105

Gittis AH, Kreitzer AC (2012) Striatal microcircuitry and movement disorders. Trends Neurosci 35(9):557-564. https://doi. org/10.1016/j.tins.2012.06.008

Gong S, Zheng C, Doughty ML, Losos K, Didkovsky N, Schambra UB, Nowak NJ, Joyner A, Leblanc G, Hatten ME, Heintz N (2003) A gene expression atlas of the central nervous system based on bacterial artificial chromosomes. Nature 425(6961):917-925. https:// doi.org/10.1038/nature02033

Groszer M, Keays DA, Deacon RM, de Bono JP, Prasad-Mulcare S, Gaub S, Baum MG, French CA, Nicod J, Coventry JA, Enard W, Fray M, Brown SD, Nolan PM, Paabo S, Channon KM, Costa RM, Eilers J, Ehret G, Rawlins JN, Fisher SE (2008) Impaired synaptic plasticity and motor learning in mice with a point mutation implicated in human speech deficits. Curr Biol 18(5):354362. https://doi.org/10.1016/j.cub.2008.01.060

Harrington AJ, Raissi A, Rajkovich K, Berto S, Kumar J, Molinaro G, Raduazzo J, Guo Y, Loerwald K, Konopka G, Huber KM, Cowan CW (2016) MEF2C regulates cortical inhibitory and excitatory synapses and behaviors relevant to neurodevelopmental disorders. Elife. https://doi.org/10.7554/eLife.20059

Heiman M, Schaefer A, Gong S, Peterson JD, Day M, Ramsey KE, Suarez-Farinas M, Schwarz C, Stephan DA, Surmeier DJ, Greengard P, Heintz N (2008) A translational profiling approach for the molecular characterization of CNS cell types. Cell 135(4):738748. https://doi.org/10.1016/j.cell.2008.10.028

Hibbert B, Fung I, McAuley R, Lariviere K, MacNeil B, Bafi-Yeboa N, Livesey J, Trudeau V (2004) Increased GAD67 mRNA levels are correlated with in vivo GABA synthesis in the MPTPtreated catecholamine-depleted goldfish brain. Brain Res Mol Brain Res 128(2):121-130. https://doi.org/10.1016/j.molbrainre s.2004.06.008

Hintiryan H, Foster NN, Bowman I, Bay M, Song MY, Gou L, Yamashita S, Bienkowski MS, Zingg B, Zhu M, Yang XW, Shih JC, Toga AW, Dong HW (2016) The mouse cortico-striatal projectome. Nat Neurosci 19(8):1100-1114. https://doi.org/10.1038/nn.4332

Hisaoka T, Nakamura Y, Senba E, Morikawa Y (2010) The forkhead transcription factors, Foxp1 and Foxp2, identify different subpopulations of projection neurons in the mouse cerebral cortex. Neuroscience 166(2):551-563. https://doi.org/10.1016/j.neuro science.2009.12.055

Hunnicutt BJ, Jongbloets BC, Birdsong WT, Gertz KJ, Zhong H, Mao T (2016) A comprehensive excitatory input map of the striatum reveals novel functional organization. Elife. https://doi. org/10.7554/eLife.19103

Jensen K, Lambert JD, Jensen MS (1999) Activity-dependent depression of GABAergic IPSCs in cultured hippocampal neurons. J Neurophysiol 82(1):42-49

Keays DA, Clark TG, Flint J (2006) Estimating the number of coding mutations in genotypic- and phenotypic-driven $N$-ethyl- $N$-nitrosourea (ENU) screens. Mamm Genome 17(3):230-238. https:// doi.org/10.1007/s00335-005-0101-4

Kreitzer AC, Malenka RC (2008) Striatal plasticity and basal ganglia circuit function. Neuron 60(4):543-554. https://doi.org/10.1016/j. neuron.2008.11.005

Krishnan K, Wang BS, Lu J, Wang L, Maffei A, Cang J, Huang ZJ (2015) MeCP2 regulates the timing of critical period plasticity that shapes functional connectivity in primary visual cortex. Proc Natl Acad Sci USA 112(34):E4782-E4791. https://doi. org/10.1073/pnas.1506499112
Lai CS, Fisher SE, Hurst JA, Vargha-Khadem F, Monaco AP (2001) A forkhead-domain gene is mutated in a severe speech and language disorder. Nature 413(6855):519-523. https://doi. org/10.1038/35097076

Lai CS, Gerrelli D, Monaco AP, Fisher SE, Copp AJ (2003) FOXP2 expression during brain development coincides with adult sites of pathology in a severe speech and language disorder. Brain 126(Pt 11):2455-2462. https://doi.org/10.1093/brain/awg247

Lalchandani RR, Vicini S (2013) Inhibitory collaterals in genetically identified medium spiny neurons in mouse primary corticostriatal cultures. Physiol Rep 1(6):e00164. https://doi.org/10.1002/ phy 2.164

Laprade N, Soghomonian JJ (1999) Gene expression of the GAD67 and GAD65 isoforms of glutamate decarboxylase is differentially altered in subpopulations of striatal neurons in adult rats lesioned with 6-OHDA as neonates. Synapse 33 (1):36-48. https://doi.org/10.1002/(SICI)1098-2396(19990 7) $33: 1 \% 3 \mathrm{C} 36::$ AID-SYN4\%3E3.0.CO;2-0

Lau CG, Murthy VN (2012) Activity-dependent regulation of inhibition via GAD67. J Neurosci 32(25):8521-8531. https://doi. org/10.1523/JNEUROSCI.1245-12.2012

Lee H, Sawatari A (2011) Medium spiny neurons of the neostriatal matrix exhibit specific, stereotyped changes in dendritic arborization during a critical developmental period in mice. Eur J Neurosci 34(9):1345-1354. https://doi.org/10.111 $1 / \mathrm{j} .1460-9568.2011 .07852 . x$

Liegeois F, Baldeweg T, Connelly A, Gadian DG, Mishkin M, Vargha-Khadem F (2003) Language fMRI abnormalities associated with FOXP2 gene mutation. Nat Neurosci 6(11):1230-1237. https://doi.org/10.1038/nn1138

Lipstein N, Verhoeven-Duif NM, Michelassi FE, Calloway N, van Hasselt PM, Pienkowska K, van Haaften G, van Haelst MM, van Empelen R, Cuppen I, van Teeseling HC, Evelein AM, Vorstman JA, Thoms S, Jahn O, Duran KJ, Monroe GR, Ryan TA, Taschenberger H, Dittman JS, Rhee JS, Visser G, Jans JJ, Brose N (2017) Synaptic UNC13A protein variant causes increased neurotransmission and dyskinetic movement disorder. J Clin Investig 127(3):1005-1018. https://doi.org/10.1172/JCI90259

Liu G (2004) Local structural balance and functional interaction of excitatory and inhibitory synapses in hippocampal dendrites. Nat Neurosci 7(4):373-379. https://doi.org/10.1038/nn1206

Maas JW, Yang J, Edwards RH (2017) Endogenous leucine-rich repeat kinase 2 slows synaptic vesicle recycling in striatal neurons. Front Synaptic Neurosci 9:5. https://doi.org/10.3389/fnsyn.2017.00005

MacDermot KD, Bonora E, Sykes N, Coupe AM, Lai CS, Vernes SC, Vargha-Khadem F, McKenzie F, Smith RL, Monaco AP, Fisher SE (2005) Identification of FOXP2 truncation as a novel cause of developmental speech and language deficits. Am J Hum Genet 76(6):1074-1080. https://doi.org/10.1086/430841

Melzer S, Gil M, Koser DE, Michael M, Huang KW, Monyer H (2017) Distinct corticostriatal GABAergic neurons modulate striatal output neurons and motor activity. Cell Rep 19(5):1045-1055. https ://doi.org/10.1016/j.celrep.2017.04.024

Morgan A, Fisher SE, Scheffer I, Hildebrand M (2017) FOXP2related speech and language disorders. In: Adam MP, Ardinger $\mathrm{HH}$, Pagon RA et al (eds) GeneReviews ${ }^{\circledR}$ [Internet]. University of Washington, Seattle

Olpe HR, Steinmann MW, Greiner K, Pozza MF (1994) Contribution of presynaptic GABA-B receptors to paired-pulse depression of GABA-responses in the hippocampus. Naunyn Schmiedebergs Arch Pharmacol 349(5):473-477

Pan WX, Mao T, Dudman JT (2010) Inputs to the dorsal striatum of the mouse reflect the parallel circuit architecture of the forebrain. Front Neuroanat 4:147. https://doi.org/10.3389/fnana.2010.00147 
Peach RK (2004) Acquired apraxia of speech: features, accounts, and treatment. Top Stroke Rehabil 11(1):49-58. https://doi. org/10.1310/ATNK-DBE8-EHUQ-AA64

Peixoto RT, Wang W, Croney DM, Kozorovitskiy Y, Sabatini BL (2016) Early hyperactivity and precocious maturation of corticostriatal circuits in Shank3B(-/-) mice. Nat Neurosci 19(5):716724. https://doi.org/10.1038/nn.4260

Reimers-Kipping S, Hevers W, Paabo S, Enard W (2011) Humanized Foxp2 specifically affects cortico-basal ganglia circuits. Neuroscience 175:75-84. https://doi.org/10.1016/j.neuroscien ce.2010.11.042

Rothwell PE, Fuccillo MV, Maxeiner S, Hayton SJ, Gokce O, Lim BK, Fowler SC, Malenka RC, Sudhof TC (2014) Autism-associated neuroligin-3 mutations commonly impair striatal circuits to boost repetitive behaviors. Cell 158(1):198-212. https://doi. org/10.1016/j.cell.2014.04.045

Rueda N, Florez J, Martinez-Cue C (2008) Chronic pentylenetetrazole but not donepezil treatment rescues spatial cognition in Ts65Dn mice, a model for down syndrome. Neurosci Lett 433(1):22-27. https://doi.org/10.1016/j.neulet.2007.12.039

Schreiweis C, Bornschein U, Burguiere E, Kerimoglu C, Schreiter S, Dannemann M, Goyal S, Rea E, French CA, Puliyadi R, Groszer M, Fisher SE, Mundry R, Winter C, Hevers W, Paabo S, Enard W, Graybiel AM (2014) Humanized Foxp2 accelerates learning by enhancing transitions from declarative to procedural performance. Proc Natl Acad Sci USA 111(39):14253-14258. https:// doi.org/10.1073/pnas.1414542111

Schroll H, Beste C, Hamker FH (2015) Combined lesions of direct and indirect basal ganglia pathways but not changes in dopamine levels explain learning deficits in patients with Huntington's disease. Eur J Neurosci 41(9):1227-1244. https://doi.org/10.1111/ ejn. 12868

Schulz SB, Haesler S, Scharff C, Rochefort C (2010) Knockdown of FoxP2 alters spine density in area $\mathrm{X}$ of the zebra finch. Genes Brain Behav 9(7):732-740. https://doi.org/10.1111/j.1601183X.2010.00607.x

Shepherd GM (2013) Corticostriatal connectivity and its role in disease. Nat Rev Neurosci 14(4):278-291. https://doi.org/10.1038/ nrn3469

Sia GM, Clem RL, Huganir RL (2013) The human language-associated gene SRPX2 regulates synapse formation and vocalization in mice. Science 342(6161):987-991. https://doi.org/10.1126/scien ce. 1245079

Smith Y, Raju DV, Pare JF, Sidibe M (2004) The thalamostriatal system: a highly specific network of the basal ganglia circuitry. Trends Neurosci 27(9):520-527. https://doi.org/10.1016/j. tins.2004.07.004

Smith Y, Raju D, Nanda B, Pare JF, Galvan A, Wichmann T (2009) The thalamostriatal systems: anatomical and functional organization in normal and parkinsonian states. Brain Res Bull 78(2-3):60-68. https://doi.org/10.1016/j.brainresbull.2008.08.015
Spiteri E, Konopka G, Coppola G, Bomar J, Oldham M, Ou J, Vernes SC, Fisher SE, Ren B, Geschwind DH (2007) Identification of the transcriptional targets of FOXP2, a gene linked to speech and language, in developing human brain. Am J Hum Genet 81(6):11441157. https://doi.org/10.1086/522237

Square-Storer PAH, Sharon C, Roy EA (1990) The dissociation of aphasia from apraxia of speech, ideomotor limb, and buccofacial apraxia. Adv Psychol 70(C):451-476

Surmeier DJ, Ding J, Day M, Wang Z, Shen W (2007) D1 and D2 dopamine-receptor modulation of striatal glutamatergic signaling in striatal medium spiny neurons. Trends Neurosci 30(5):228-235. https://doi.org/10.1016/j.tins.2007.03.008

Takahashi K, Liu FC, Hirokawa K, Takahashi H (2003) Expression of Foxp2, a gene involved in speech and language, in the developing and adult striatum. J Neurosci Res 73(1):61-72. https://doi. org/10.1002/jnr.10638

Taverna S, Ilijic E, Surmeier DJ (2008) Recurrent collateral connections of striatal medium spiny neurons are disrupted in models of Parkinson's disease. J Neurosci 28(21):5504-5512. https://doi. org/10.1523/JNEUROSCI.5493-07.2008

Vargha-Khadem F, Gadian DG, Copp A, Mishkin M (2005) FOXP2 and the neuroanatomy of speech and language. Nat Rev Neurosci 6(2):131-138. https://doi.org/10.1038/nrn1605

Vernes SC, Nicod J, Elahi FM, Coventry JA, Kenny N, Coupe AM, Bird LE, Davies KE, Fisher SE (2006) Functional genetic analysis of mutations implicated in a human speech and language disorder. Hum Mol Genet 15(21):3154-3167. https://doi.org/10.1093/hmg/ dd1392

Vernes SC, Spiteri E, Nicod J, Groszer M, Taylor JM, Davies KE, Geschwind DH, Fisher SE (2007) High-throughput analysis of promoter occupancy reveals direct neural targets of FOXP2, a gene mutated in speech and language disorders. Am J Hum Genet 81(6):1232-1250. https://doi.org/10.1086/522238

Vernes SC, Oliver PL, Spiteri E, Lockstone HE, Puliyadi R, Taylor JM, Ho J, Mombereau C, Brewer A, Lowy E, Nicod J, Groszer M, Baban D, Sahgal N, Cazier JB, Ragoussis J, Davies KE, Geschwind DH, Fisher SE (2011) Foxp2 regulates gene networks implicated in neurite outgrowth in the developing brain. PLoS Genet 7(7):e1002145. https://doi.org/10.1371/journal.pgen.10021 45

Yang Y, Calakos N (2013) Presynaptic long-term plasticity. Front Synaptic Neurosci 5:8. https://doi.org/10.3389/fnsyn.2013.00008

Zhang Z, Jiao YY, Sun QQ (2011) Developmental maturation of excitation and inhibition balance in principal neurons across four layers of somatosensory cortex. Neuroscience 174:10-25. https://doi. org/10.1016/j.neuroscience.2010.11.045

Zhang K, Chammas C, Soghomonian JJ (2015) Loss of glutamic acid decarboxylase (Gad67) in striatal neurons expressing the Drdr1a dopamine receptor prevents L-DOPA-induced dyskinesia in 6-hydroxydopamine-lesioned mice. Neuroscience 303:586-594. https://doi.org/10.1016/j.neuroscience.2015.07.032 